See discussions, stats, and author profiles for this publication at: https://www.researchgate.net/publication/333328995

\title{
Energy assessment and environmental impact analysis of an R134a/R744 cascade refrigeration plant upgraded with the low-GWP refrigerants R152a, R1234ze(E), propane (R290) and propyl...
}

Article in International Journal of Refrigeration · May 2019

DOI: 10.1016/j.jirefrig.2019.05.028

CITATIONS

0

5 authors, including:

Daniel Sánchez

Universitat Jaume

97 PUBLICATIONS 913 CITATIONS

SEE PROFILE

Rodrigo Llopis Doménech

Universitat Jaume I

115 PUBLICATIONS 1,081 CITATIONS

SEE PROFILE
READS

71

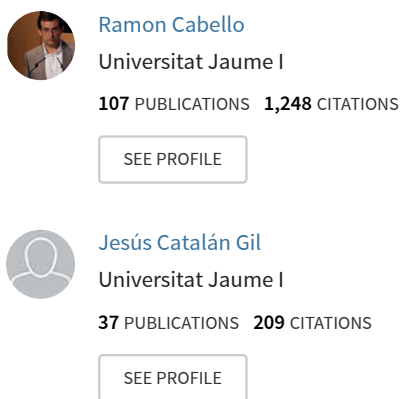

Some of the authors of this publication are also working on these related projects:

Special Issue: Frontiers in Energy Research: Advances in Refrigeration Technologies for Climate Change Mitigation View project

Special Issue (Frontiers in Energy Research): Advances in Refrigeration Technologies for Climate Change Mitigation View project 


\title{
Energy assessment and environmental impact analysis of an $R 134 a / R 744$ cascade refrigeration plant upgraded with the low-GWP refrigerants $R 152 a, R 1234 z e(E)$, propane ( $R 290)$ and propylene (R1270)
}

\author{
D. Sánchez ${ }^{a *}$, R. Cabello ${ }^{a}$, R. Llopis ${ }^{a}$, J. Catalán-Gil $^{a}$, L. Nebot-Andrés ${ }^{a}$ \\ aJaume I University, Dep. of Mechanical Engineering and Construction, Campus de Riu Sec s/n \\ E-12071, Castellón, Spain
}

*Corresponding author: sanchezd@uji.es Tel.: +34 964 728142; Fax.: +34 964728106

\begin{abstract}
The European limitations associated with the use of fluorinated refrigerants have affected one of the most extended solutions used in commercial refrigeration in warm countries. Traditional cascade systems with R404A or R134a, in the high-temperature cycle, and R744 $\left(\mathrm{CO}_{2}\right)$, in the low side, will be prohibited from 2022 onwards unless the refrigerants used have a $\mathrm{GWP}_{100}$ lower than 150 . Since practically all the available refrigerants with low-GWP 100 are flammable, a simple but effective modification can be adopted upgrading the current direct expansion system to an indirect one. Accordingly, the aim of this work is to determine the energy and environmental impact of converting an $\mathrm{R} 134 \mathrm{a} / \mathrm{CO}_{2}$ direct expansion cascade to an indirect one using the low-GWP 100 refrigerants R152a, R1234ze(E), R290 and R1270. The experimental analysis is performed at three different heat rejection temperatures (from 23.3 to $43.6 \stackrel{\circ}{ } \mathrm{C}$ ), maintaining the cooling service product at temperatures of $2{ }^{\circ} \mathrm{C}$ and $-20 \circ \mathrm{C}$ on average.
\end{abstract}

\section{KEYWORDS}

Cascade, Indirect expansion, R152a, R1234ze(E), R290, R1270

\section{HIGHLIGHTS}

- Conversion of a direct R134a/R744 cascade to an indirect one is analysed energetically.

- Low-GWP ${ }_{100}$ refrigerants R152a, R1234ze(E), R290 and R1270 are also analysed.

- Indirect arrangement increases the energy consumption from $+2.5 \%$ to $+17.1 \%$.

- The Indirect arrangement reduces the refrigerant mass charge on average $58.5 \%$.

- The environmental impact (TEWI) of the indirect arrangement is reduced by $30 \%$.

- R152a is the best option for an indirect upgrading. 


\section{Nomenclature}

$\begin{array}{cc}\text { COP } & \text { coefficient of performance } \\ \text { DX } & \text { direct expansion } \\ \text { E } & \text { energy consumption }(\mathrm{kW} \cdot \mathrm{h}) \\ \text { GWP } & \text { global warming potential } \\ \text { HFO } & \text { hydrofluoroolefins } \\ \text { HT } & \text { high-temperature } \\ \text { HX } & \text { heat-exchanger } \\ \text { IX } & \text { indirect expansion } \\ \text { L } & \text { annual leakage rate } \\ \text { LF } & \text { load factor } \\ \text { LT } & \text { low-temperature } \\ \text { m } & \text { refrigerant mass charge }(\mathrm{kg}) \\ \mathrm{n} & \text { operating time horizon } \\ \text { P } & \text { pressure (bar) / power consumption }(\mathrm{W}) \\ \text { PAG } & \text { polyalkylene glycol oil } \\ \text { POE } & \text { polyolester oil } \\ \dot{\mathrm{q}} & \text { volumetric flow rate }\left(\mathrm{m}^{3} \cdot \mathrm{h}^{-1}\right) \\ \text { RH } & \text { relative humidity } \\ \text { t } & \text { time }(\mathrm{sec}) \\ \text { T } & \text { temperature }(-\mathrm{C}) \\ \text { TEWI } & \text { Total Equivalent Warming Impact }\end{array}$

Greek Symbols

$\Delta$

$\alpha$

$\beta$ variation (increment or decrement)

refrigerant recycling factor

indirect emission factor $\left(\mathrm{kg} \mathrm{CO}_{2} / \mathrm{kW} \cdot \mathrm{h}\right)$

\section{Subscripts}

\begin{tabular}{cc}
\hline Cab & cabinet \\
Cas & cascade \\
cham & climatic chamber \\
CO2 & LT-cycle \\
Com & compressor \\
Dis & discharge \\
dry-bulb & it refers to dry-bulb temperature \\
HT & high temperature cycle \\
in & inlet / inner \\
K & condenser \\
LT & low temperature cycle \\
MT & medium temperature \\
O & evaporator \\
Pump & secondary fluid pump \\
RefHT & HT-cycle \\
SF & secondary fluid \\
Total & total \\
W & water
\end{tabular}




\section{Introduction}

Cascade refrigeration systems are widely used in commercial refrigeration because of their compactness and their ability to provide two different cooling demands at medium and low temperature with high values of COP compared with single-stage vapour compression cycles [1]. They consist of two vapour compression cycles thermally connected by a heat exchanger commonly known as a cascade heat exchanger. The low-temperature cycle (LT-cycle) provides cooling capacity at the low-temperature level $(\sim-35 \circ C)$ while the high-temperature cycle (HTcycle) provides cooling capacity at the medium temperature level $(\sim-10 \circ \mathrm{C})$. Since both cycles are independent, the refrigerant used in each one can be improved according to the operating conditions in order to maximize the global COP of the facility. Thus, for LT-cycle, $\mathrm{CO}_{2}$ is commonly used due to its low-cost, environmental advantages and the high working pressures at low temperatures. For the HT-cycle, R134a (GWP ${ }_{100}$ : 1300) and R404A (GWP ( $_{100}$ : 3943), as well as its corresponding drop-ins, are the most used solutions due to its feasibility, availability and good performance [2-4]. However, at present, Regulation EU no. 517/2014 (F-Gas) [5] restricts the use of fluorinated refrigerants in cascade systems depending on its arrangement. According to Section 13 of Annex II, for direct expansion configurations with a rated capacity of $40 \mathrm{~kW}$ or more, the maximum GWP 100 of refrigerants used in both cycles are limited to 150 . If an indirect expansion is used, Regulation introduces an exception that includes primary circuits for cascade systems where fluorinated gases with $\mathrm{GWP}_{100}$ below 1500 may be used. Considering how widely used R134a and R404A are used as the primary refrigerants in cascade refrigerating plants, it is necessary to replace those refrigerants with others allowed by the FGas Regulation. Nevertheless, the vast majority of low-GWP solutions for existing refrigeration plants are classified as flammable [6,7], so the progress towards a $\mathrm{CO}_{2}$ direct emission reduction turns into a flammability problem where ATEX certification must be used.

Focusing on cascade refrigeration systems, there are several works where flammable refrigerants are used in the high-temperature cycle in accordance with the limitations presented above. Thus, Bingming et al. [8] and Dopazo and Fernández-Seara [9] experimentally evaluated the performance of an $\mathrm{NH}_{3} / \mathrm{CO}_{2}$ cascade refrigeration system driven by screw compressors (first) and reciprocating compressors (second). The results obtained for a range of evaporating temperatures from -50 to -30 ㅇ $\mathrm{C}$ justify in both cases the convenience of using cascade systems instead of single-stage systems, for evaporating temperatures below -35/$40^{\circ} \mathrm{C}$. Cabello et al. [10] also evaluated experimentally the use of R152a as drop-in of R134a in an $\mathrm{R} 134 \mathrm{a} / \mathrm{CO}_{2}$ cascade refrigeration facility. The results revealed that R152a performs better as the temperature difference between the hot and cold source is greater. Moreover, the discharge temperature of R152a is approximately 10 to 15 ㅇ C greater than R134a, which entails the need for a better cooling system for the high-temperature compressor. Bhattacharyya et al. [11] from a theoretical point of view studied an $\mathrm{R} 290 / \mathrm{CO}_{2}$ cascade system for simultaneous refrigeration and heating. The results provide an optimum operating condition and demonstrate that $\mathrm{R} 290$ offers a wider operating range instead of $\mathrm{NH}_{3}$ for simultaneous refrigeration and heating. Dubey et al. [12] also from a theoretical approach, analyze the possibility of using a transcritical $\mathrm{CO}_{2} / \mathrm{R} 1270$ cascade using propylene as the refrigerant of the low-temperature cycle. The results confirmed better system performance than subcritical cascade cycle. Xiao et al. [13] presented a theoretical analysis of an $\mathrm{R} 32 / \mathrm{CO}_{2}$ cascade working 
at different operating conditions. Recently, Bellos and Tzivanidis [14] theoretically assessed different alternatives for a $\mathrm{CO}_{2} / \mathrm{CO}_{2}$ cascade system replacing the refrigerant of the HT-cycle. In this case 17 pairs of refrigerants where analyzed energetically and environmentally verifying that the refrigerants $\mathrm{R} 152 \mathrm{a}, \mathrm{NH}_{3}, \mathrm{R} 1270, \mathrm{R} 600, \mathrm{R} 600 \mathrm{a}$ and $\mathrm{R} 290$ are the most suitable to reduce the refrigerating plant energy consumption and the overall environmental impact.

In commercial refrigeration systems where both evaporative levels are used to provide cooling capacity at medium and low-temperature levels, the use of a direct expansion with flammable refrigerants is prohibited for security reasons. Accordingly, a simple but effective solution consists in using an indirect expansion system in the medium temperature level, where a secondary fluid is cooled by the main cycle and then pumped to the corresponding cooling services $[15,16]$. This arrangement allows reducing substantially the refrigerant's leak rate up to $90 \%$ [17] as well as the amount of refrigerant used in the system [18]. However, indirect layout uses a fluid pump and an additional heat exchanger that increases the energy consumption of the refrigerating facility due to the power consumed by the pump and the extra temperature difference required in the secondary fluid cooler [19-21].

Once again, focusing on cascade systems, Zhang [22] published a theoretical study comparing different refrigerating systems including a parallel rack with R404A in direct expansion and an $\mathrm{R} 290 / \mathrm{CO}_{2}$ cascade with $\mathrm{CO}_{2}$ as secondary fluid in the medium temperature level. The results from the study revealed that cascade indirect system only supposed an increment of $1 \%$ in terms of energy with a TEWI reduction of 66.6\%. Beshr et al. [23] from a theoretical approach, compare an $\mathrm{R} 448 \mathrm{~A} / \mathrm{CO}_{2}$ direct expansion system with an indirect one using pumped $\mathrm{CO}_{2}$ for the medium temperature level. Their results showed that for ambient temperatures higher than $5^{\circ} \mathrm{C}$ the indirect cascade offered the best energy performance. Sawalha et al. [24] experimentally tested an indirect $\mathrm{NH}_{3} / \mathrm{CO}_{2}$ cascade system under laboratory conditions, using an indirect $\mathrm{CO}_{2}$ pumped loop for the medium temperature services. The results were compared with a single-stage R404A system for medium and low temperature using an indirect loop for the medium temperature service. From tests, the cascade system offers up to $60 \%$ better performance than the R404A configuration. Finally, Sánchez et al. [25] also compared experimentally the energy impact of converting an $\mathrm{R} 134 \mathrm{a} / \mathrm{CO}_{2}$ direct expansion cascade to an indirect one using Propylene-glycol $40 \%$ and Temper ${ }^{\circledR}-20$ as secondary fluids for the medium temperature level. The results obtained at three different rejection temperatures maintaining a cabinet for fresh-product and a freezer cabinet, revealed an increment in the energy consumption up to $14 \%$ for Propylene-glycol and up to $11.1 \%$ for Temper ${ }^{\circledast}$.

Despite the large number of works summarized below, there is a limited number of experimental analysis that evaluate energetically the use of low-GWP refrigerants in a cascade HT-cycle. Accordingly, the aim of this work is focused on analyzing the energy consumption of an indirect $\mathrm{R} 134 \mathrm{a} / \mathrm{CO}_{2}$ cascade when the $\mathrm{R} 134 \mathrm{a}$ is replaced with different low-GWP alternatives including R152a, R1234ze(E), R290 and R1270. To carry out this aim, an R134a/CO direct expansion cascade designed to provide cooling capacity at two cooling services at $2^{\circ} \mathrm{C}$ and $-20^{\circ} \mathrm{C}$ has been used as reference. Tests were performed quantifying the energy consumption of each configuration working during 24 hours at three different heat rejection 
temperatures. To sum up the analysis, an environmental impact study was performed determining the TEWI index at three Spanish cities assuming different operating conditions.

\section{Experimental setup and test methodology}

\subsection{Experimental setup}

The refrigerating plant used to perform the experimental tests is a conventional R134a/R744 cascade system equipped with two vapour compressor cycles thermally connected by a brazed-plate heat exchanger (from now on HX-cascade) (7) as can be shown in Figure 1. The low-temperature cycle (LT-cycle) is designed to operate with $\mathrm{CO}_{2}$ with a direct expansion arrangement in a frozen-product glass-door cabinet with a cooling capacity of $1.5 \mathrm{~kW}$ and dimensions of 1875 (L) $\times 1170$ (H) $\times 1000$ (W) mm. The cycle is composed by a semi-hermetic compressor (9), an oil separator (10), a gas-cooler to cool down the refrigerant before to enter in the HX-cascade [26] (11), a liquid receiver of 12 litters (12), an electronic expansion valve (13), and a finned-tube heat exchanger installed inside the frozen cabinet (14). As will be stated in section 2.3, the rotation speed of the $\mathrm{CO}_{2}$ compressor was fixed to $1300 \mathrm{rpm}$ in all the performed tests in order to adjust the cooling provided with the cooling demand. This reduction may slightly penalize the compressor global efficiency, but it is necessary since no smaller semi-hermetic compressor has been found.

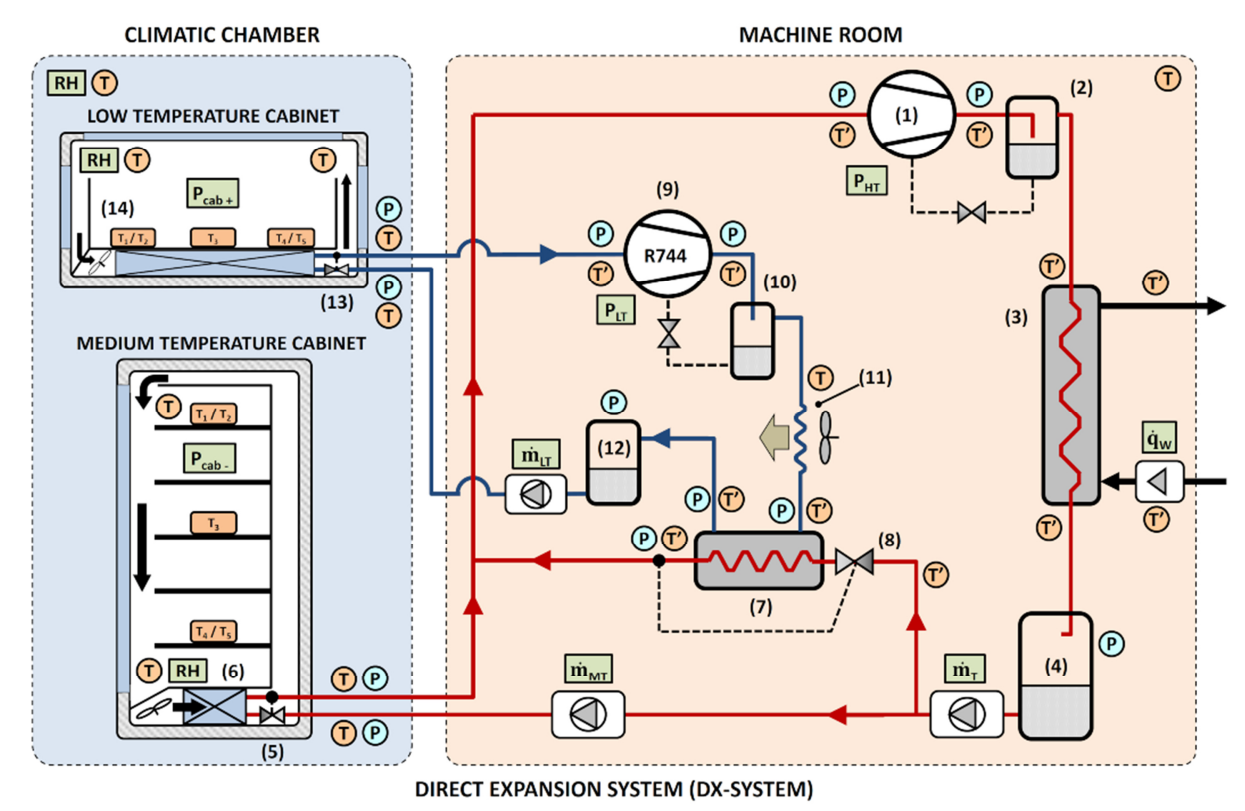

Figure 1. Schematic diagram of the cascade's refrigeration cycle with direct expansion arrangement

The high-temperature cycle (HT-cycle) is designed to cool down simultaneously the LT-cycle and a fresh-product glass-door cabinet with a total cooling capacity of $2 \mathrm{~kW}$ and dimensions of $1875(\mathrm{~L}) \times 2071(\mathrm{H}) \times 890(\mathrm{~W}) \mathrm{mm}$. The refrigerant used in this circuit is R134a with a direct expansion arrangement according to the schematic diagram of Figure 1 . In this case, the cycle is composed by a semi-hermetic compressor (1), an oil separator (2), a brazed-plate condenser (3), a liquid receiver of 19 litters (4), two electronic expansion valves ( 8 and 5), and two parallel evaporators that provides the cooling effect to the medium temperature cabinet (finned-tube 
heat exchanger) (6) and to the low temperature cycle (HX-cascade) (7). The expansion valves are managed by a controller that is upgraded according to the refrigerant used. The semihermetic compressor of the HT-cycle has been selected to cover the heat rejected by the LTcycle and the cooling demand from the medium temperature cabinet working with the direct expansion arrangement. The refrigerant used in this selection was R134a.

Both cabinets were installed inside a class 3 climatic chamber [27] that maintains a relative humidity of $55 \%$ and a dry temperature of $25 \circ \mathrm{C}$ throughout the experimental tests.

Figure 2 presents the simplified diagram of the modified cascade refrigeration system with a closed indirect expansion system (from now on IX-system). As can be noted, the new arrangement has an extra close loop that thermally connects the refrigeration facility with the medium temperate cabinet. This loop includes a brazed-plate evaporator (16), a recirculation pump (15), a " $Y$ " filter, an expansion vessel and a finned-tube heat exchanger similar to the one used in the DX-system (17). The secondary fluid used in the experimental tests was Temper $^{\circledR}$-20. The main refrigerants tested in the HT-cycle were R134a, R152a and R1234ze(E) using the same semi-hermetic compressor installed in the direct expansion arrangement. For R290 and R1270, the compressor was changed to one with ATEX-certification. The displacement of this compressor was set to $6.71 \mathrm{~m}^{3} \cdot \mathrm{h}^{-1}$ in order to extend its use to other hydrocarbons with lower volumetric capacity. However, it should be highlighted that this value can be reduced.

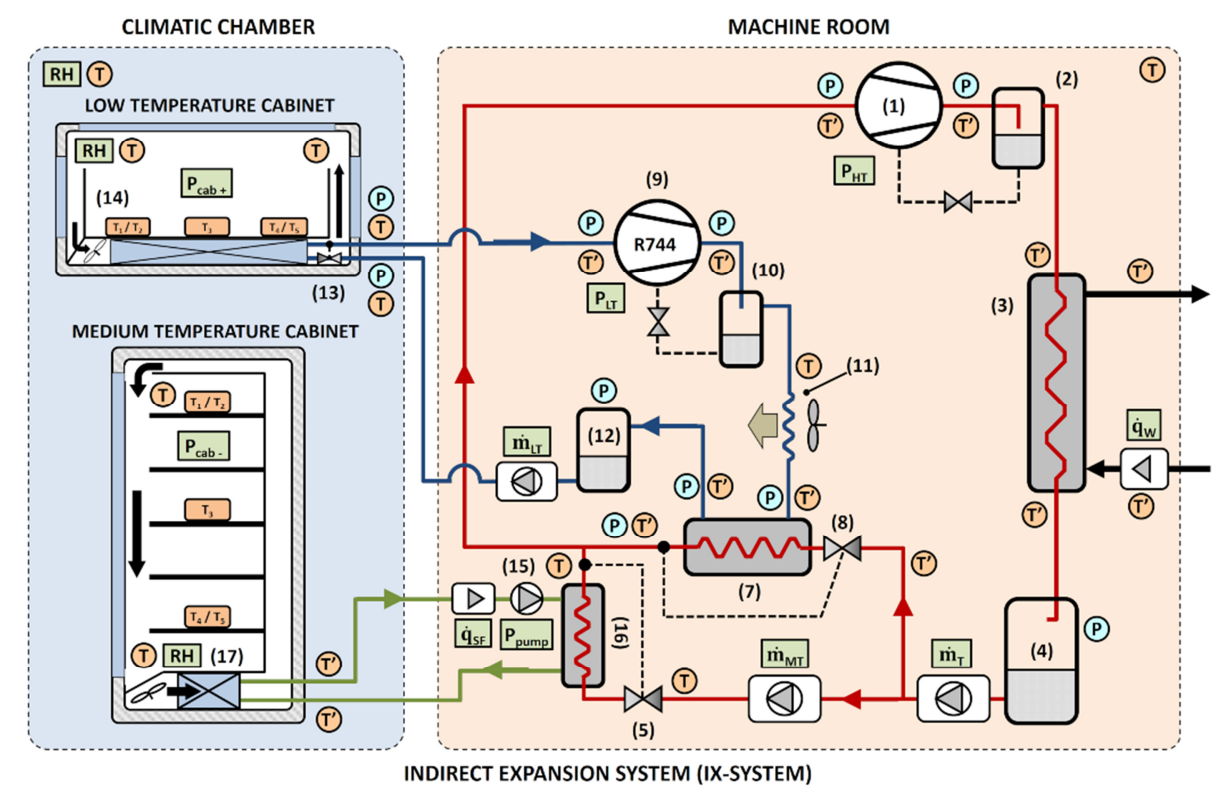

Figure 2. Schematic diagram of the cascade's refrigeration cycle working with indirect expansion arrangement

Table 1 summarizes the main characteristics of the components installed in the facility. The IXsystem has a liquid receiver smaller than the DX-system according to [17]. 


\begin{tabular}{|c|c|c|c|}
\hline Number & Component & Location & Description \\
\hline 1 & Semihermetic compressor & HT-cycle & $\begin{array}{l}\text { For HFCs: BITZER compressor with } 6.5 \mathrm{~m}^{3} \cdot \mathrm{h}^{-1}(1450 \mathrm{rpm}) \text { Oil: POE SL32. } \\
\text { For HCs: DORIN compressor with } 6.71 \mathrm{~m}^{3} \cdot \mathrm{h}^{-1}(1450 \mathrm{rpm}) \text { Oil: PAG } 68 .\end{array}$ \\
\hline $2 / 10$ & Oil separator & HT-cycle & The oil separator is different depending on the compressor. \\
\hline 3 & Brazed-plate condenser & HT-cycle & SWEP heat exchanger with 40 plates and $2.39 \mathrm{~m}^{2}$ of heat transfer area. \\
\hline 4 & Liquid receiver & HT-cycle & $19 \mathrm{dm}^{3}$ for DX-system and $11 \mathrm{dm}^{3}$ for IX-system. \\
\hline $5 / 8 / 13$ & Electronic expansion valve & HT/LT-cycle & Electronic valve CAREL working as thermostatic. \\
\hline 6 & Finned-tube evaporator & HT-cycle & $\begin{array}{l}\text { SEREVA heat exchanger with a tube of } 5 / 8^{\prime} \text { staggered array and a fine } \\
\text { spacing of } 8 \mathrm{~mm} \text {. Inner tube heat transfer area: } 1.76 \mathrm{~m}^{2} .\end{array}$ \\
\hline 7 & Brazed-plate cascade & HT/LT-cycle & SWEP heat exchanger with 30 plates and $1.76 \mathrm{~m}^{2}$ of heat transfer area. \\
\hline 9 & Semihermetic compressor & LT-cycle & DORIN compressor with $1.12 \mathrm{~m}^{3} \cdot \mathrm{h}^{-1}$ (1450 rpm) Oil: POE C85E. \\
\hline 11 & Finned-tube gas-cooler & LT-cycle & $\begin{array}{l}\text { SEREVA heat exchanger with a tube of } 1 / 4^{\prime} \text { staggered array and a fine } \\
\text { spacing of } 3 \mathrm{~mm} \text {. Inner tube heat transfer area: } 0.6 \mathrm{~m}^{2} \text {. }\end{array}$ \\
\hline 12 & Liquid receiver & LT-cycle & $12 \mathrm{dm}^{3}$ with external cooling for high ambient temperatures (if necessary) \\
\hline 14 & Finned-tube evaporator & LT-cycle & $\begin{array}{l}\text { SEREVA heat exchanger with a tube of } 3 / 8^{\prime} \text { staggered array and a fine } \\
\text { spacing of } 8 \mathrm{~mm} \text {. Inner tube heat transfer area: } 1.35 \mathrm{~m}^{2} .\end{array}$ \\
\hline 15 & Secondary fluid pump & SF-loop & $\begin{array}{l}\text { WILO recirculation pump with a maximum flow rate of } 2 \mathrm{~m}^{3} \cdot \mathrm{h}^{-1} \text { and a } \\
\text { maximum supply pressure of } 13 \mathrm{wcm} .\end{array}$ \\
\hline 16 & Brazed-plate evaporator & SF-loop & SWEP heat exchanger with 30 plates and $1.79 \mathrm{~m}^{2}$ of heat transfer area. \\
\hline
\end{tabular}

Table 1. Characteristics of the components installed in the cascade refrigeration system

\subsection{Measurement elements}

The refrigeration facility presented in Figures 1 and 2 is fully instrumented. The location of the sensors in the experimental setup is depicted in Figures 1 and 2 where $(P)$ means pressure, $(T)$ and $\left(\mathrm{T}^{\prime}\right)$ temperature, $(\mathrm{RH})$ relative humidity, $\left(\mathrm{P}_{\mathrm{xx}}\right)$ electrical power consumption, $(\dot{q})$ volumetric flow rate and $(\dot{m})$ mass flow rate. Table 2 gathers the measurement range and the accuracy of these elements according to the manufacturer's data.

\begin{tabular}{|c|c|c|c|}
\hline Measured Variable & Measurement device & Calibration Range & Calibrated accuracy \\
\hline Temperature & T-type thermocouple & -40 to $125 \stackrel{\circ}{ } \mathrm{C}$ & $\pm 0.5 \stackrel{\circ}{\circ}$ \\
\hline Pressure (HT-cycle) & Pressure gauge & 0 to 25 bar & \pm 0.15 bar \\
\hline Pressure (HT-cycle) & Pressure gauge & 0 to 10 bar & \pm 0.06 bar \\
\hline Pressure (LT-cycle) & Pressure gauge & 0 to 100 bar & \pm 0.60 bar \\
\hline Pressure (LT-cycle) & Pressure gauge & 0 to 60 bar & \pm 0.36 bar \\
\hline Mass flow rate (HT-cycle) & Coriolis mass flow meter & 0 to $0.5 \mathrm{~kg} \cdot \mathrm{s}^{-1}$ & $\pm 0.1 \%$ of reading \\
\hline Mass flow rate (LT-cycle) & Coriolis mass flow meter & 0 to $0.15 \mathrm{~kg} \cdot \mathrm{s}^{-1}$ & $\pm 0.1 \%$ of reading \\
\hline Volume flow rate & Magnetic flow meter & 0 to $6 \mathrm{~m}^{3} \cdot \mathrm{h}^{-1}$ & $\pm 0.25 \%$ of reading \\
\hline Secondary fluid flow rate & Magnetic flow meter & 0 to $20 \mathrm{I} \cdot \mathrm{min}^{-1}$ & $\pm 0.25 \%$ of reading \\
\hline $\begin{array}{l}\text { Power consumption } \\
\text { (compressors) }\end{array}$ & Network analyser & 0 to $2000 \mathrm{~W}$ & $\pm 0.5 \%$ of reading \\
\hline Power consumption (cabinets) & Network analyser & 0 to $2500 \mathrm{~W}$ & $\pm 0.5 \%$ of reading \\
\hline $\begin{array}{l}\text { Power consumption (secondary } \\
\text { fluid pump) }\end{array}$ & Network analyser & 0 to $100 \mathrm{~W}$ & $\pm 0.1 \%$ of reading \\
\hline Environmental temperature and & Humidity/Temperature & 5 to $90 \%$ & $\pm 0.2 \%$ \\
\hline relative humidity & transducer & -20 to $80 \stackrel{\circ}{C}$ & $\pm 0.2 \circ \mathrm{C}$ \\
\hline
\end{tabular}

Table 2 - Measurement elements

Temperature sensors marked as $(T)$ are placed over pipes and insulated from the environment with foam with an average thermal conductivity of $0.04 \mathrm{~W} \cdot \mathrm{m}^{-1} \cdot \mathrm{K}^{-1}$ according to ISO 13787. Thermocouples marked as $\left(\mathrm{T}^{\prime}\right)$, are installed inside the refrigeration facility in direct contact with the fluid (refrigerant or secondary fluid). For the measurement of the product 
temperature, 10 certified M-test packages (ISO-15502) with T-type thermocouples and dimensions of $200 \times 100 \times 50 \mathrm{~mm}$ were used.

Data from sensors are acquired by a data acquisition system cRIO-9074 from National Instruments ${ }^{\circledR}$ connected to a personal computer with a register time of 5 seconds. Thermophysical properties of the refrigerant and the secondary fluids are calculated with the software RefProp v.9.1 [28] and SecCool v.1.33 [29].

\subsection{Test methodology}

To compare the energy consumption of both configurations, a series of energy consumption tests were performed in a wide range of operating conditions. These tests consist of measuring the energy consumption of the refrigerating plant during 24 hours under certain operating conditions that includes three heat rejection temperatures $(18.8,31.6$ and $42.2 \circ \mathrm{C})$ and a temperature of $2{ }^{\circ} \mathrm{C}$ for fresh-product and $-20 \circ \mathrm{C}$ for frozen-product. Those temperatures were obtained as an average on the $10 \mathrm{M}$-test packages fixing the set point of the cabinet controller to $1^{\circ} \mathrm{C}$ for the MT-cabinet and -23 으 $\mathrm{C}$ for the LT-cabinet.

To adopt this kind of methodology the following considerations have been taken into account:

- Cabinets: Regardless of the configuration adopted, the cabinet controls the indoor air with an on/off controller that enables or disables the cooling system. Thus, for DX-system the controller manages the electronic expansion valve (4) installed in the finned-tube heat exchanger (5 and 10), while for the IX-system it handles the electronic expansion valve of the brazed-plate evaporator (11). The useful superheating adopted in each controller was $7 \mathrm{~K}$ for the MT-cabinet and $15 \mathrm{~K}$ for the LT-cabinet. Additionally, controllers manage the defrosting process with electrical resistors every 8 hours. The defrosting period ends when the temperature over the cabinet's finned-tube heat exchanger reaches $5^{\circ} \mathrm{C}$.

- Cascade heat exchanger: The evaporation process in the cascade heat exchanger is controlled by an electronic expansion valve with useful superheating of $5 \mathrm{~K}$. The condensing process has been left free with no control on the subcooling.

- Compressors: LT and MT compressors are controlled by two pressure switches installed at the compressor suction port with an on/off strategy depending on the pressure level. Thus, for the MT-compressor the pressure switch was adjusted to provide a low-cut temperature of $-21^{\circ} \mathrm{C}$ and a cut-in temperature of $-3.5^{\circ} \mathrm{C}$ regardless of the refrigerant used. For the LT-compressor the low-cut temperature was adjusted to $-42^{\circ} \mathrm{C}$ and the cut-in temperature to $-32^{\circ} \mathrm{C}$. In both cases, the oil return was controlled automatically by the oil separators installed in the discharge line (Figures 1 and 2). The rotation speed of the LTcompressor was $1300 \mathrm{rpm}$ while the rotation speed for the MT-compressor was $1450 \mathrm{rpm}$.

- Secondary fluid pump: For the presented analysis the secondary fluid pump has been maintained always on excepting during the defrosting period. Since the pump is a variablespeed one, the flow rate of the secondary fluid was set to $2 \mathrm{I} \cdot \mathrm{min}^{-1}$ in all cases. 
- External heat rejection conditions: The water used in the brazed-plate condenser is controlled by an external unit that maintains the desired temperature and flow rate of the fluid. The present analysis covers a wide range of heat rejection temperatures $\left(T_{W_{i}}\right): 18.8$, 31.6 and $42.2^{\circ} \mathrm{C}$, maintaining a constant flow rate of $1 \mathrm{~m}^{3} \cdot \mathrm{h}^{-1}$.

- Testing sequence: The sequence of tests performed in the cascade refrigeration facility was distributed as follows: $1^{\text {st }}$ direct expansion in MT using R134a. $2^{\text {nd }}$ indirect expansion in MT using R134a. $3^{\text {rd }}$ similar to the previous one but using R152a as a refrigerant in MT. $4^{\text {th }}$ similar to the previous one but using R1234ze(E) in MT. $5^{\text {th }}$ indirect expansion in MT using R290 as a refrigerant in an ATEX-certified compressor. Finally, $6^{\text {th }}$, similar to the previous one but using R1270 as a refrigerant. In all cases, $\mathrm{CO}_{2}$ has been used in direct expansion. Before starting with a new refrigerant, the frost from cabinets was removed maintaining an ambient temperature of $25 \circ \mathrm{C}$.

\section{Experimental results}

To evaluate experimentally the energy consumption of each configuration, a total set of 18 tests were performed according to the considerations described in subsection 2.3. Table 3 summarizes the reference parameters averaged from tests including their standard deviation.

\begin{tabular}{|c|c|c|c|c|c|c|c|c|c|c|c|c|c|c|}
\hline \multicolumn{15}{|c|}{ REFERENCE PARAMETERS } \\
\hline R134a - DX & 18.8 & \pm 0.2 & 1.0 & \pm 0.0 & 53.4 & \pm 5.2 & 24.9 & \pm 0.8 & 2.1 & \pm 0.1 & -19.7 & \pm 0.4 & & \\
\hline R152a - IX & 18.8 & \pm 0.2 & 1.0 & \pm 0.0 & 53.6 & \pm 5.1 & 24.8 & \pm 0.8 & 1.9 & \pm 0.1 & -19.9 & \pm 0.4 & 2.0 & \pm 0.2 \\
\hline R1234ze(E) - IX & 18.7 & \pm 0.2 & 1.0 & \pm 0.0 & 53.6 & \pm 5.1 & 25.0 & \pm 0.8 & 2.0 & \pm 0.1 & -20.0 & \pm 0.3 & 2.0 & \pm 0.2 \\
\hline R134a-DX & 31.4 & \pm 0.4 & 1.0 & \pm 0.0 & 53.4 & \pm 5.1 & 25.0 & \pm 0.7 & 2.0 & \pm 0.1 & -19.7 & \pm 0.4 & & \\
\hline R134a-IX & 31.7 & \pm 0.3 & 1.0 & \pm 0.0 & 52.8 & \pm 5.3 & 25.3 & \pm 0.8 & 2.1 & \pm 0.1 & -19.9 & \pm 0.3 & 1.9 & \pm 0.2 \\
\hline R152a - IX & 31.7 & \pm 0.2 & 1.0 & \pm 0.0 & 53.5 & \pm 5.2 & 24.8 & \pm 0.8 & 2.0 & \pm 0.1 & -19.8 & \pm 0.4 & 2.0 & \pm 0.2 \\
\hline R1234ze(E) - IX & 31.6 & \pm 0.2 & 1.0 & \pm 0.0 & 53.4 & \pm 5.1 & 25.0 & \pm 0.8 & 2.0 & \pm 0.1 & -19.9 & \pm 0.3 & 1.9 & \pm 0.2 \\
\hline R290 - IX & 31.8 & \pm 0.2 & 1.0 & \pm 0.0 & 53.2 & \pm 4.9 & 24.9 & \pm 0.9 & 2.1 & \pm 0.1 & -20.0 & \pm 0.3 & 2.0 & \pm 0.2 \\
\hline R1234ze(E) - IX & 42.3 & \pm 0.1 & 1.0 & \pm 0.0 & 53.0 & \pm 5.1 & 25.0 & \pm 0.7 & 2.2 & \pm 0.1 & -19.9 & \pm 0.3 & 1.9 & \pm 0.2 \\
\hline R290 - IX & 42.2 & \pm 0.2 & 1.0 & \pm 0.0 & 53.1 & \pm 4.8 & 25.0 & \pm 0.9 & 2.1 & \pm 0.1 & -19.6 & \pm 0.5 & 2.0 & \pm 0.2 \\
\hline R1270 - IX & 42.1 & \pm 0.2 & 1.0 & \pm 0.0 & 51.2 & \pm 4.6 & 25.0 & \pm 0.9 & 2.1 & \pm 0.1 & -19.8 & \pm 0.3 & 2.1 & \pm 0.2 \\
\hline
\end{tabular}

Table 3 - Reference parameters

Due to the significant number of data, this section has divided into fourth subsections. The first one is devoted to analysing the temperature indicators as the discharge temperature of each compressor and the change-phase temperatures in the cabinets. The second one is devoted to comparing the power consumption of the different active elements: compressors, cabinets and secondary fluid pump. The third subsection is focused on the energy consumption of the refrigeration plant according to the different configurations. And finally, the last subsection presents an environmental analysis based on the index of TEWI. 


\subsection{Temperature indicators}

For each configuration three temperatures have been analysed: the condensing temperature, the evaporating level and the discharge temperature.

The condensing temperatures of the HT-cycle ( $T_{\text {K.HT }}$ ) and the LT-cycle ( $T_{\text {Cas.LT }}$ ) have been obtained assuming liquid saturated conditions using the pressure measurements. Similarly, the evaporating temperature of the LT-cycle ( $\left.T_{\text {Cab.LT }}\right)$ has been calculated with the pressure measurements of vapour assuming vapour saturated conditions. Finally, the evaporating temperatures at the cascade heat exchanger $\left(T_{\text {Cas.HT }}\right)$ and the medium temperature service $\left(\mathrm{T}_{\text {Cab.HT }}\right)$ were obtained from the pressure measurements assuming vapour saturated conditions. If the indirect expansion is adopted, both evaporating temperatures are assumed equal since the heat exchangers of the cascade and the secondary fluid are installed in parallel and they share the same pressures at the inlet/outlet ports. However, if a direct expansion arrangement is used, each evaporating temperature is calculated using the vapour pressure measurements at the evaporator outlet port. The adoption of this methodology allows considering the pressure drops introduced by the pipe lines installed from the machinery room to the MT-service.

Additionally, the temperature difference in the cascade heat exchanger $\left(\Delta \mathrm{T}_{\text {cas }}\right)$ has been included as a relevant indicator. This temperature difference has been determined through the Expression 1 with the condensing temperature of the LT-cycle ( $T_{\text {Cas.LT }}$ ) and the evaporating temperature at the cascade heat exchanger ( $\left.T_{\text {Cas.HT }}\right)$.

$$
\Delta \mathrm{T}_{\text {Cas }}=\mathrm{T}_{\text {Cas.LT }}-\mathrm{T}_{\text {Cas.HT }}
$$

All the measured data have been averaged during the 24-hour tests only when both compressors are running to reduce the variability of data. Table 4 summarizes all the indicators commented above including its standard deviation during tests.

\begin{tabular}{|c|c|c|c|c|c|c|c|c|c|c|c|c|c|c|c|c|c|c|}
\hline \multirow{2}{*}{$\begin{array}{c}\text { Configuration } \\
\text { R134a - DX }\end{array}$} & \multicolumn{2}{|c|}{$T_{W . i n}(\stackrel{o}{ })$} & \multicolumn{2}{|c|}{$T_{\text {K.HT }}(\stackrel{\circ}{ }=$} & \multicolumn{2}{|c|}{$T_{\text {Dis.HT }}\left(\stackrel{\circ}{ }{ }^{\circ}\right)$} & \multicolumn{2}{|c|}{$T_{\text {Cab.HT }}\left(\stackrel{\circ}{ }{ }^{-}\right)$} & \multicolumn{2}{|c|}{$\mathrm{T}_{\text {Cas.HT }}(\stackrel{\circ}{ } \mathrm{C})$} & \multicolumn{2}{|c|}{$\mathrm{T}_{\text {Cas.LT }}(\stackrel{\circ}{ } \mathrm{C})$} & \multicolumn{2}{|c|}{$T_{\text {Dis.LT }}(\stackrel{\circ}{ }=$} & \multicolumn{2}{|c|}{$T_{\text {Cab.LT }}\left(\stackrel{\circ}{ }{ }^{\prime}\right)$} & \multicolumn{2}{|c|}{$\Delta \mathbf{T}_{\text {Cas }}(\mathrm{K})$} \\
\hline & 18.8 & \pm 0.2 & 21.5 & \pm 0.4 & 69.4 & \pm 2.7 & -10.9 & \pm 2.5 & -13.3 & \pm 2.8 & -11.0 & \pm 2.7 & 82.8 & \pm 5.2 & -37.4 & \pm 4.1 & 2.2 & \pm 2.6 \\
\hline R134a - IX & 18.8 & \pm 0.2 & 21.3 & \pm 0.4 & 65.7 & \pm 3.2 & & -16.1 & \pm 2.4 & & -11.8 & \pm 2.5 & 76.8 & \pm 7.9 & -38.5 & \pm 4.2 & 4.2 & \pm 2.5 \\
\hline R152a - IX & 18.8 & \pm 0.2 & 22.3 & \pm 0.3 & 69.3 & \pm 3.5 & & -12.8 & \pm 2.5 & & -10.0 & \pm 2.2 & 81.8 & \pm 6.4 & -37.1 & \pm 4.1 & 3.3 & \pm 2.3 \\
\hline R1234ze(E) - IX & 18.7 & \pm 0.2 & 27.6 & \pm 0.4 & 62.7 & \pm 2.1 & & -11.2 & \pm 2.3 & & -7.4 & \pm 2.5 & 87.1 & \pm 5.4 & -36.8 & \pm 3.6 & 4.0 & \pm 2.5 \\
\hline R290 - IX & 18.9 & \pm 0.2 & 22.0 & \pm 0.5 & 61.3 & \pm 2.9 & & -14.3 & \pm 2.9 & & -10.9 & \pm 2.4 & 86.2 & \pm 6.5 & -37.1 & \pm 3.9 & 3.7 & \pm 2.7 \\
\hline R1270 - IX & 18.9 & \pm 0.2 & 22.5 & \pm 0.5 & 66.0 & \pm 4.2 & & -14.0 & \pm 2.5 & & -12.2 & \pm 2.5 & 83.1 & \pm 5.4 & -37.0 & \pm 4.4 & 2.2 & \pm 2.6 \\
\hline R134a-DX & 31.4 & \pm 0.4 & 33.7 & \pm 0.8 & 82.2 & \pm 2.9 & -9.2 & \pm 1.7 & -11.9 & \pm 2.0 & -10.5 & \pm 2.3 & 83.0 & \pm 5.6 & -37.8 & \pm 3.7 & 2.1 & \pm 2.6 \\
\hline R134a - IX & 31.7 & \pm 0.3 & 33.5 & \pm 0.8 & 79.3 & \pm 2.0 & & -16.2 & \pm 1.8 & & -9.0 & \pm 2.5 & 81.4 & \pm 5.1 & -34.7 & \pm 3.6 & 3.4 & \pm 1.9 \\
\hline R152a - IX & 31.7 & \pm 0.2 & 34.6 & \pm 1.9 & 83.6 & \pm 3.3 & & -10.5 & \pm 2.9 & & -7.8 & \pm 2.0 & 84.3 & \pm 5.6 & -36.0 & \pm 4.4 & 3.1 & \pm 1.8 \\
\hline R1234ze(E) - IX & 31.6 & \pm 0.2 & 37.8 & \pm 0.3 & 71.1 & \pm 1.7 & & -9.7 & \pm 1.7 & & -5.6 & \pm 2.3 & 88.2 & \pm 6.7 & -36.7 & \pm 4.1 & 4.1 & \pm 2.2 \\
\hline R290 - IX & 31.8 & \pm 0.2 & 34.8 & \pm 0.9 & 72.9 & \pm 3.4 & & -13.1 & \pm 3.0 & & -10.2 & \pm 2.1 & 87.6 & \pm 5.8 & -37.2 & \pm 3.9 & 3.0 & \pm 2.0 \\
\hline R1270 - IX & 31.6 & \pm 0.2 & 34.8 & \pm 0.5 & 79.4 & \pm 4.8 & & -14.3 & \pm 2.6 & & -12.2 & \pm 2.5 & 81.9 & \pm 5.6 & -37.1 & \pm 4.1 & 2.1 & \pm 1.8 \\
\hline R134a-DX & 42.2 & \pm 0.3 & 44.6 & \pm 0.7 & 93.0 & \pm 1.7 & -8.7 & \pm 1.7 & -11.3 & \pm 1.8 & -9.5 & \pm 2.1 & 83.3 & \pm 6.2 & -37.4 & \pm 2.4 & 1.6 & \pm 2.4 \\
\hline R134a - IX & 42.0 & \pm 0.3 & 43.9 & \pm 0.9 & 83.3 & \pm 1.5 & & -15.4 & \pm 0.7 & & -5.8 & \pm 0.9 & 81.9 & \pm 1.1 & -35.9 & \pm 1.5 & 2.9 & \pm 1.8 \\
\hline R152a - IX & 42.2 & \pm 0.1 & 45.0 & \pm 1.7 & 95.6 & \pm 2.1 & & -8.7 & \pm 1.8 & & -6.5 & \pm 1.1 & 84.9 & \pm 5.4 & -34.3 & \pm 4.3 & 2.8 & \pm 1.6 \\
\hline R1234ze(E) - IX & 42.3 & \pm 0.1 & 47.4 & \pm 0.2 & 80.8 & \pm 1.1 & & -7.7 & \pm 1.8 & & -3.4 & \pm 2.3 & 79.1 & \pm 5.8 & -34.1 & \pm 5.6 & 4.6 & \pm 2.4 \\
\hline R290 - IX & 42.2 & \pm 0.2 & 45.1 & \pm 0.5 & 82.3 & \pm 3.3 & & -11.4 & \pm 3.1 & & -9.0 & \pm 2.4 & 92.0 & \pm 4.7 & -36.6 & \pm 3.9 & 2.6 & \pm 1.9 \\
\hline R1270 - IX & 42.1 & \pm 0.2 & 45.3 & \pm 0.5 & 89.6 & \pm 5.1 & & -13.1 & \pm 2.9 & & -10.5 & \pm 2.4 & 83.5 & \pm 5.4 & -36.9 & \pm 3.9 & 2.7 & \pm 1.8 \\
\hline
\end{tabular}


Figures 3 and 4 graphically represent the phase-change temperatures from Table 4 where the base cycle (DX-system) is presented in a solid colour with a dotted line. The error bars plotted in both Figures are the standard deviation from Table 4.

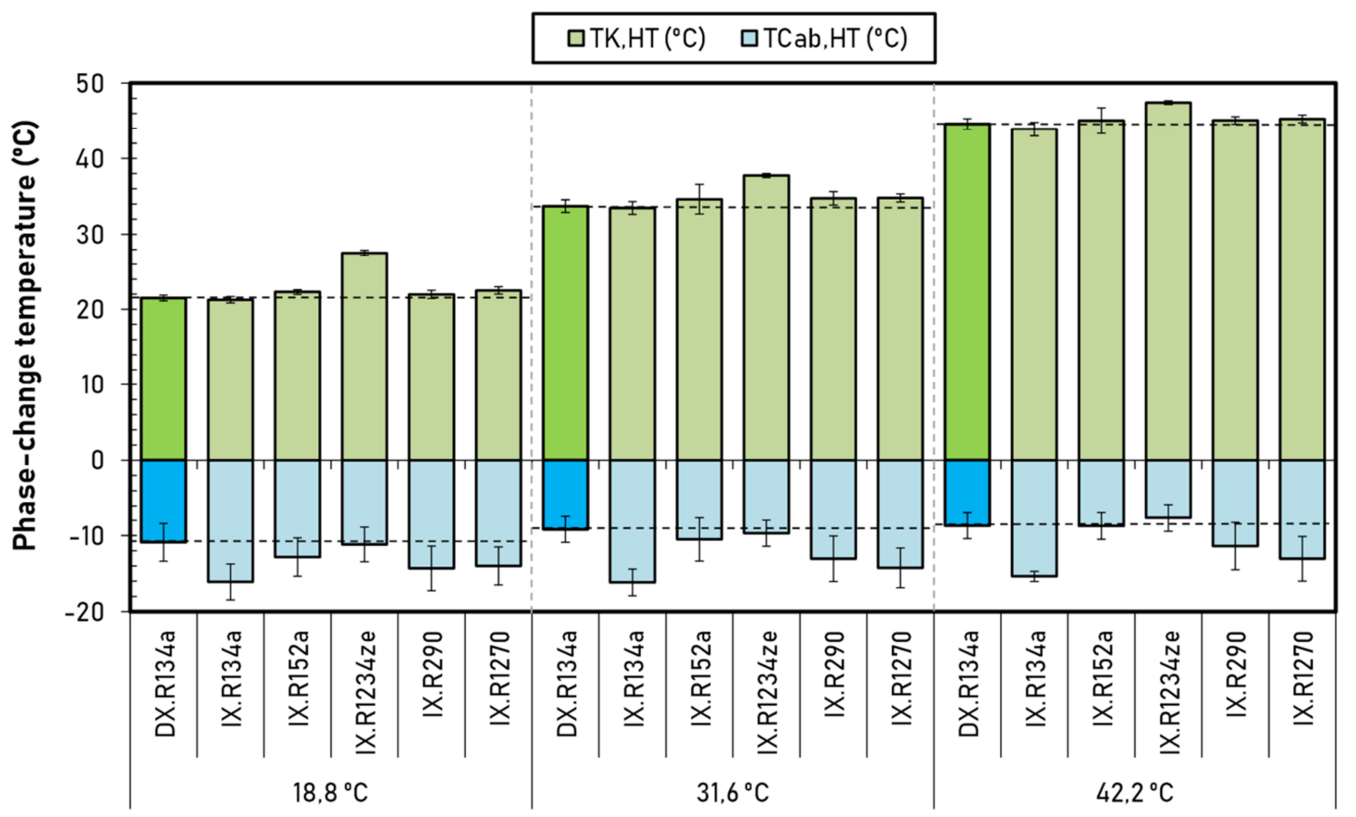

Heat rejection temperature $\left(T_{W, \text { in }}\right)\left({ }^{\circ} \mathrm{C}\right)$

Figure 3. Phase change temperatures for the HT-cycle

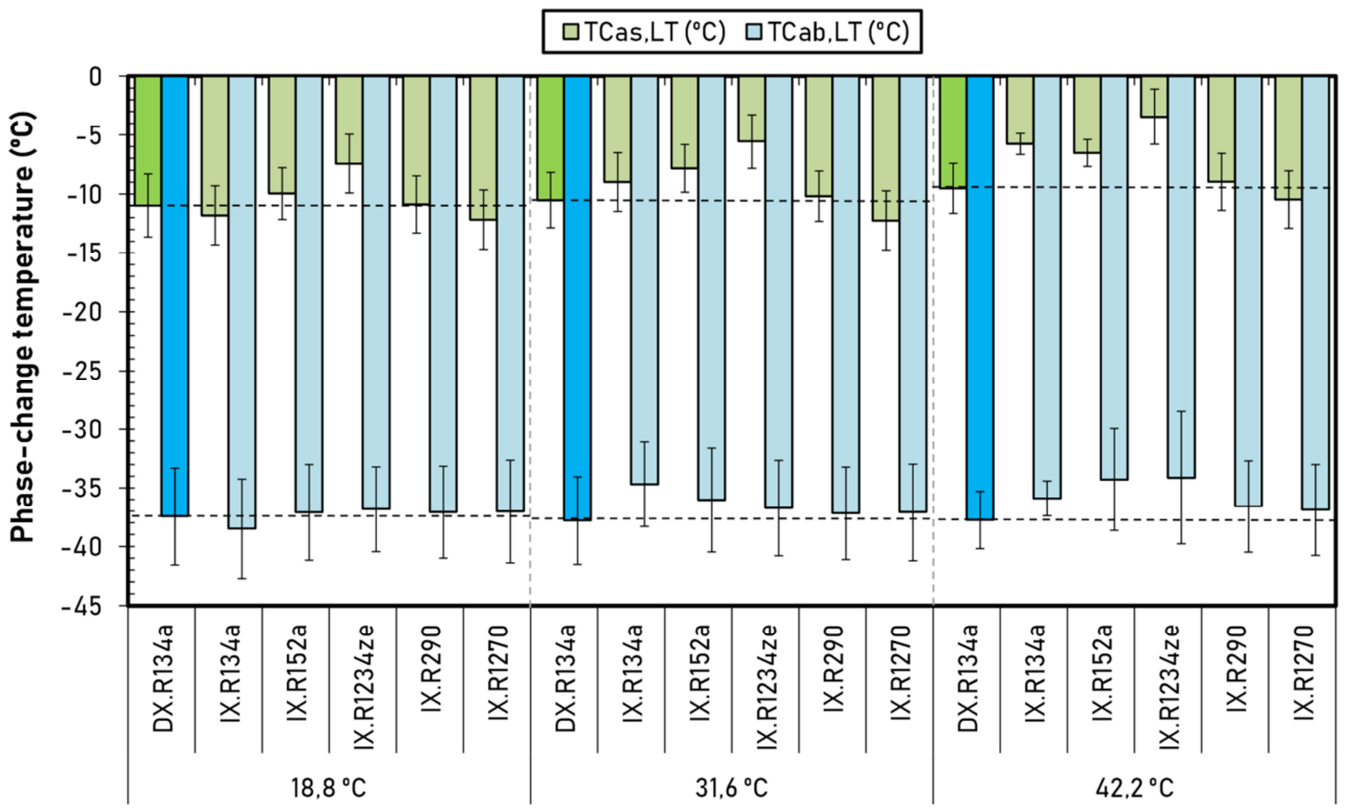

Heat rejection temperature $\left(\mathrm{T}_{\mathrm{W}, \mathrm{in}}\right)\left({ }^{\circ} \mathrm{C}\right)$

Figure 4. Phase change temperatures for the LT-cycle

Taking into account the information presented in Table 4 and Figures 3 and 4, some aspects can be highlighted. At first, the use of a direct expansion system provides two evaporating 
temperatures at the medium temperature level: $T_{\text {Cab.HT }}$ and $T_{\text {Cas.Hт. }}$. This difference is due to the pressure drops and the heat gains introduced by the pipe lines installed from the machinery room to the MT-service. Thus, as shown in Table 4, the evaporating temperature of the medium temperature cabinet $\left(T_{\text {Cab.HT }}\right)$ is always higher ( $+2.6 \mathrm{~K}$ higher) than the evaporating level of the cascade heat exchanger ( $\left.T_{\text {Cas.HT }}\right)$. In case of using and indirect arrangement, this difference is negligible since the cascade heat exchanger and the heat exchanger for the secondary fluid are installed in parallel within the refrigeration plant.

Secondly, focusing on the HT-cycle with R134a, the use of additional fluid to cool down the MT-service reduces the evaporating temperature of the cabinet ( $\left.T_{\text {Cab.нт }}\right) 6.3 \mathrm{~K}$ on average due to the addition of an extra temperature difference in the system. The main consequence of this variation can be seen in Figure 4 for the LT-cycle where the levels of evaporation and condensation grow up to $3.1 \mathrm{~K}$ and $3.8 \mathrm{~K}$, respectively, with regard to the DX-system levels. Notwithstanding, due to the transient operation of the refrigerating plant, it is difficult to predict with accuracy these trends.

Regarding the use of different refrigerants in the HT-cycle for the indirect arrangement, is evident that the HFC R134a decreases the the evaporating level of the HT-cycle while the HFO R1234ze(E) raises it. That means that the heat transfer area for this last refrigerant should be greater than the actual value, which is in accordance with the work presented previously by Sánchez et al. [30] in an IX-system for a medium temperature service. Focusing on the refrigerant R152a, it maintains a similar condensing level compared to the other refrigerants but with a higher evaporating temperature. Finally, the use of hydrocarbons R290 and R1270 increase the evaporating level of the HT-cycle with regard to the IX-system with R134a.

Concerning the LT-cycle, the transient operation of the system makes difficulty to obtain relevant trends in temperatures $T_{\mathrm{Ca}, L T}$ and $T_{\mathrm{Cab}, \mathrm{LT}}$. Notwithstanding it seems that the use of $\mathrm{R} 1234 \mathrm{ze}(\mathrm{E})$ or R152a in the HT-cycle increases the condensing and evaporating temperature with a trend similar to R134a. Hydrocarbons R290 and R1270 do not show important variations with regard to R134a and their values are almost invariable with regard to the heat rejection temperature.

The third temperature indicator selected for the analysis is the discharge temperature. According to Figure 5, the discharge temperature rises with the heat rejection temperature in both compressors due to the increment of the condensing pressure. In general, the conversion from DX-system to an indirect one reduces slightly the discharge temperature of both compressors. The use of R152a as a refrigerant in the HT-cycle rises the discharge temperature up to $2.7 \mathrm{~K}$, while the use of $\mathrm{R} 1234 \mathrm{ze}(\mathrm{E})$ reduces it up to $12.1 \mathrm{~K}$ on average. 


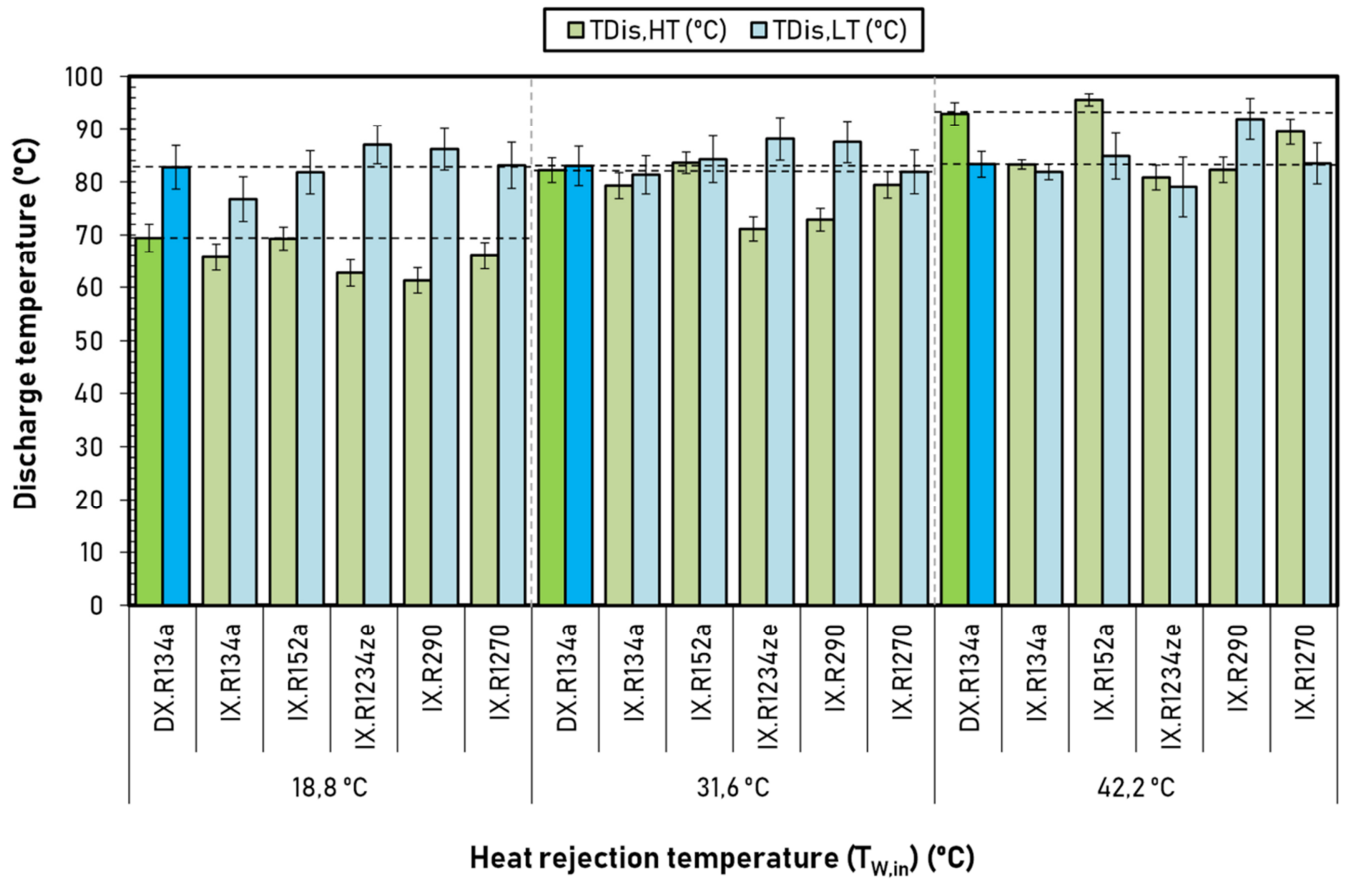

Figure 5. Discharge temperatures for the HT and LT-cycle

Finally, the temperature difference in the cascade heat exchanger indicates how effective the heat transfer process through the heat exchanger is. Since the evaporating pressure of the HTcycle will depend on the capacity of the medium temperature service and the heat rejected by the LT-cycle, the data presented in Table 4 always consider both compressors running.

Taking into account the experimental results, it can be shown that the conversion from a direct expansion system to an indirect one entails an increment of the $\Delta \mathrm{T}_{\text {cas }}$ value regardless of the heat rejection temperature tested. Moreover, the use of different refrigerants in the HT-cycle also affects the $\Delta T_{\text {cas }}$ value with a minimum average value of $\sim 0 \mathrm{~K}$ for R1270 and a maximum difference of $3 \mathrm{~K}$ for R1234ze(E). These results reveal that the use of R1234ze(E) requires more heat transfer area in order to reduce the temperature difference. Notwithstanding, it must be remarked that no important differences between $\Delta T_{\text {Cas }}$ have been detected.

\subsection{Energy consumption}

The energy consumption of the refrigerating plant depends on the power consumption of the active elements and their operating time. Since the experimental data is acquired every 5 seconds, energy consumption of each individual element ' $i$ ' can be evaluated numerically by means of Expression 2 as a summation of $n$-terms using the trapezoidal integration method. In this expression ' $P$ ' means the active element, ' $\mathrm{t}$ ' is the time when the data is acquired and ' $\mathrm{j}$ ' is referred to each data measurement during the 24-hour tests.

$$
E_{i}=\frac{1}{36 \cdot 10^{5}} \cdot \int_{0}^{24 h} P_{i}(t) \cdot d t \simeq \frac{1}{36 \cdot 10^{5}} \cdot \sum_{j=1}^{24 h}\left\{\left[\frac{P_{i}(j)+P_{i}(j-1)}{2}\right] \cdot[t(j)-t(j-1)]\right\}
$$


Table 5 presents the average power consumption of each element averaged in a 24-hour period excepting the power consumption of compressors which were averaged only when they are in operation.

\begin{tabular}{|c|c|c|c|c|c|c|c|c|c|c|c|c|}
\hline \multicolumn{13}{|c|}{ ELECTRICAL POWER CONSUMPTION } \\
\hline Configuration & \multicolumn{2}{|c|}{$\mathrm{T}_{\mathrm{W} . \mathrm{in}}(\mathrm{\circ} \mathrm{C})$} & \multicolumn{2}{|c|}{$\mathbf{P}_{\text {com.HT }}(\mathbf{W})$} & \multicolumn{2}{|c|}{$\mathbf{P}_{\text {Cab.HT }}(\mathbf{W})$} & \multicolumn{2}{|c|}{$\mathbf{P}_{\text {com.lT }}(\mathbf{W})$} & \multicolumn{2}{|c|}{$P_{\text {Cab.LT }}(W)$} & \multicolumn{2}{|c|}{$P_{\text {Pump }}(W)$} \\
\hline R134a-DX & 18.8 & \pm 0.2 & 942 & \pm 60 & 91 & \pm 6 & 683 & \pm 73 & 438 & \pm 7 & & \\
\hline R134a-IX & 18.8 & \pm 0.2 & 945 & \pm 63 & 80 & \pm 6 & 657 & \pm 79 & 432 & \pm 12 & 7 & \pm 0 \\
\hline R152a-IX & 18.8 & \pm 0.2 & 888 & \pm 39 & 80 & \pm 6 & 673 & \pm 63 & 436 & \pm 9 & 7 & \pm 0 \\
\hline R1234ze(E) - IX & 18.7 & \pm 0.2 & 841 & \pm 28 & 80 & \pm 6 & 682 & \pm 55 & 437 & \pm 9 & 7 & \pm 0 \\
\hline R290 - IX & 18.9 & \pm 0.2 & 1208 & \pm 118 & 79 & \pm 6 & 666 & \pm 68 & 440 & \pm 8 & 7 & \pm 0 \\
\hline R1270 - IX & 18.9 & \pm 0.2 & 1407 & \pm 169 & 81 & \pm 6 & 659 & \pm 72 & 441 & \pm 8 & 7 & \pm 0 \\
\hline R134a-DX & 31.4 & \pm 0.4 & 1081 & \pm 65 & 91 & \pm 6 & 669 & \pm 72 & 433 & \pm 11 & & \\
\hline R134a-IX & 31.7 & \pm 0.3 & 1105 & \pm 69 & 80 & \pm 6 & 667 & \pm 72 & 430 & \pm 11 & 7 & \pm 0 \\
\hline R152a-IX & 31.7 & \pm 0.2 & 1055 & \pm 52 & 80 & \pm 6 & 681 & \pm 62 & 436 & \pm 9 & 7 & \pm 0 \\
\hline R1234ze(E) - IX & 31.6 & \pm 0.2 & 943 & \pm 31 & 80 & \pm 6 & 687 & \pm 64 & 435 & \pm 14 & 7 & \pm 0 \\
\hline R290 - IX & 31.8 & \pm 0.2 & 1404 & \pm 78 & 80 & \pm 6 & 670 & \pm 54 & 441 & \pm 8 & 7 & \pm 0 \\
\hline R1270 - IX & 31.6 & \pm 0.2 & 1631 & \pm 129 & 80 & \pm 6 & 649 & \pm 72 & 439 & \pm 8 & 7 & \pm 0 \\
\hline R134a-DX & 42.2 & \pm 0.3 & 1200 & \pm 69 & 90 & \pm 6 & 675 & \pm 66 & 431 & \pm 13 & & \\
\hline R134a-IX & 42.0 & \pm 0.3 & 1238 & \pm 65 & 80 & \pm 6 & 694 & \pm 52 & 439 & \pm 8 & 7 & \pm 0 \\
\hline R152a-IX & 42.2 & \pm 0.1 & 1194 & \pm 52 & 80 & \pm 6 & 709 & \pm 58 & 441 & \pm 7 & 7 & \pm 0 \\
\hline R1234ze(E) - IX & 42.3 & \pm 0.1 & 1030 & \pm 29 & 80 & \pm 6 & 720 & \pm 53 & 438 & \pm 8 & 7 & \pm 0 \\
\hline R290 - IX & 42.2 & \pm 0.2 & 1572 & \pm 100 & 81 & \pm 6 & 673 & \pm 71 & 438 & \pm 8 & 7 & \pm 0 \\
\hline R1270 - IX & 42.1 & \pm 0.2 & 1853 & \pm 121 & 81 & \pm 6 & 668 & \pm 73 & 440 & \pm 7 & 7 & \pm 0 \\
\hline
\end{tabular}

Table 5 - Electrical power consumption of the main active elements

From the results presented in Table 5 it can be noted that the average power consumption of cabinets and secondary fluid pump remain practically constant during tests. It means that the effect of defrosting periods is similar in all configurations and no special differences have been found between direct and indirect arrangements. However, the effect over the compressors is noticeable, especially for the compressor installed at the HT-cycle. According to Table 5, the conversion from a direct system to an indirect one entails a reduction of the electrical power consumed by the HT-compressor as the heat rejection temperature increases. This reduction can be rated between +0.7 and $-3.6 \%$ while the effect over the LT-compressor increases its power consumption from $-5.9 \%$ to $+7.9 \%$.

The use of different low-GWP alternatives on the HT-cycle mainly affects the power consumption of the HT-compressors. Thus, it can be clearly seen that the hydrocarbons R290 and R1270 increase the power consumption of the HT-compressor up to $+34.5 \%$ and $+57.3 \%$, respectively, regarding the direct expansion arrangement with R134a. A similar trend can be assessed for R152a which power consumption varies from $-2.5 \%$ to $+3.4 \%$. On the other hand, the use of R1234ze(E) provokes a reduction rated from $-8.1 \%$ to $-11.5 \%$ being the best option to reduce the power consumption of the HT-compressor.

Focusing on the operating time of the main components, cabinets of MT and LT are always running since they are equipped with air-fans, interior lights and anti-fogging electrical resistors. The secondary fluid pump is operating $98.9 \%$ of the test-time excepting in the defrosting process. Finally, the percentage of operating time or duty cycle for the compressors is showed in Figure 6 remarking the running time of the DX-system with R134a. 


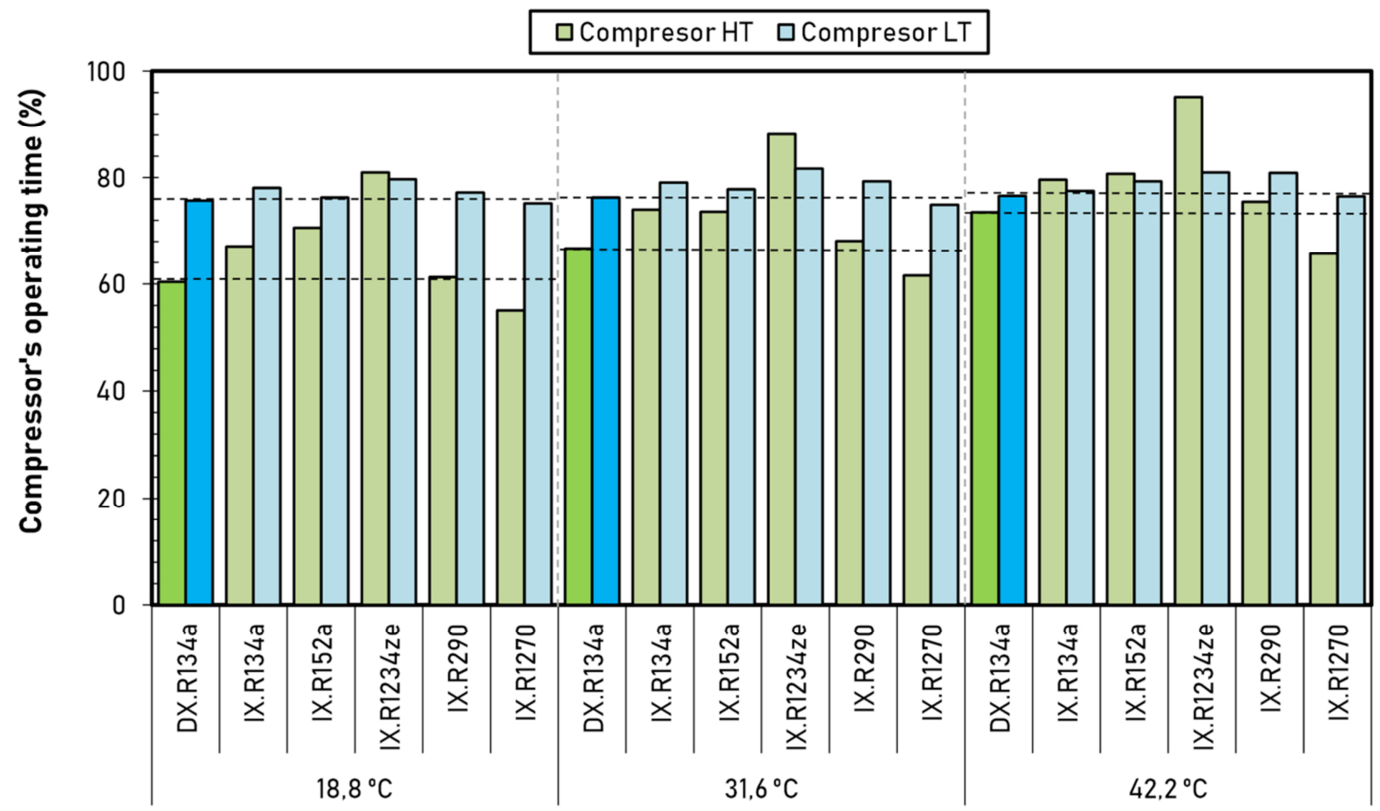

Heat rejection temperature $\left(\mathrm{T}_{\mathrm{W}, \text { in }}\right)\left({ }^{\circ} \mathrm{C}\right)$

Figure 6. Duty-cycle of compressors

Comparing direct and indirect arrangements with R134a, it is obvious that upgrading the refrigeration facility from a direct to an indirect system entails an increment in the compressor's duty-cycle. The main reason of this difference is the reduction of the evaporation temperature on the HT-cycle ( $\left.T_{\text {O.cab }}\right)$, which affects the cooling capacity of the system and consequently, the operation time of compressors. This evidence is in accordance with the results published previously by authors in a cascade refrigeration system [24].

Regarding the use of different refrigerants in the HT-cycle, the refrigerants R134a, R152a, R1234ze(E) or R290 increase the operation time of the HT-compressor, but in the case of the $\mathrm{R} 1234 z e(E)$ the effect is more prominent with increments rated between $+29.5 \%$ and $+34.1 \%$. This effect is related with the volumetric capacity of R1234ze(E) which is lower than the other refrigerants tested. Accordingly, a higher compressor displacement is necessary to compensate for it.

Using the hydrocarbon R290 as a refrigerant, the operation time is slightly higher than the DXsystem (2.1\% in average), but the use of propylene (R1270) reduces the operating time of the compressor in a range from $-7.6 \%$ to $-10.6 \%$. The main reason of this difference can be found in the volumetric capacity of the hydrocarbon compressor which is higher than the required by the refrigerating facility.

In terms of LT-compressor, all the configurations tested in this work increment its operating time excepting the use of R1270 which reports a reduction up to $-1.8 \%$. The maximum increment is reported with $\mathrm{R} 1234 \mathrm{ze}(\mathrm{E})$ with a maximum of $+7.1 \%$. 
Finally, Table 6 presents the energy consumption of active elements during the 24-hour tests with the corresponding relative error obtained indirectly by using the partial derivative analysis. The Compressor's drivers, defrosting system and cabinet's control units are also included in the energy consumption of each element.

\begin{tabular}{|c|c|c|c|c|c|c|c|c|c|c|c|c|c|c|}
\hline \multicolumn{15}{|c|}{ ENERGY CONSUMPTION DURING 24 HOURS } \\
\hline \multirow{2}{*}{$\frac{\text { Configuration }}{\text { R134a-DX }}$} & \multicolumn{2}{|c|}{$T_{W . i n}(\stackrel{\circ}{ })$} & \multicolumn{2}{|c|}{$\mathrm{E}_{\text {Cот.нт }}(\mathbf{k W} \cdot \mathbf{h})$} & \multicolumn{2}{|c|}{$E_{\text {Cab.HT }}(\mathbf{k W} \cdot \mathbf{h})$} & \multicolumn{2}{|c|}{$E_{\text {Com.LT }}(\mathbf{k W} \cdot \mathbf{h})$} & \multicolumn{2}{|c|}{$\mathrm{E}_{\mathrm{Cab.LT}}(\mathbf{k W \cdot h )}$} & \multicolumn{2}{|c|}{$E_{\text {Pump }}(k W \cdot h)$} & \multicolumn{2}{|c|}{$\mathrm{E}_{\text {Total }}(\mathrm{kW} \cdot \mathrm{h})$} \\
\hline & 18.8 & \pm 0.2 & 13.2 & \pm 0.03 & 2.5 & \pm 0.01 & 12.6 & \pm 0.05 & 11.9 & \pm 0.01 & & & 40.2 & \pm 0.12 \\
\hline R134a - IX & 18.8 & \pm 0.2 & 14.8 & \pm 0.03 & 2.2 & \pm 0.01 & 12.5 & \pm 0.04 & 11.7 & \pm 0.01 & 0.2 & \pm 0.0 & 41.4 & \pm 0.12 \\
\hline$R 152 a-I X$ & 18.8 & \pm 0.2 & 14.6 & \pm 0.03 & 2.4 & \pm 0.01 & 12.3 & \pm 0.04 & 11.7 & \pm 0.01 & 0.2 & \pm 0.0 & 41.2 & \pm 0.12 \\
\hline R1234ze(E) - IX & 18.7 & \pm 0.2 & 16.0 & \pm 0.03 & 2.4 & \pm 0.01 & 13.0 & \pm 0.04 & 11.8 & \pm 0.01 & 0.2 & \pm 0.0 & 43.4 & \pm 0.12 \\
\hline R290 - IX & 18.9 & \pm 0.2 & 17.3 & \pm 0.03 & 2.4 & \pm 0.01 & 12.5 & \pm 0.04 & 12.0 & \pm 0.01 & 0.2 & \pm 0.0 & 44.4 & \pm 0.12 \\
\hline R1270 - IX & 18.9 & \pm 0.2 & 18.1 & \pm 0.03 & 2.6 & \pm 0.01 & 12.1 & \pm 0.04 & 11.9 & \pm 0.01 & 0.2 & \pm 0.0 & 44.9 & \pm 0.13 \\
\hline R134a-DX & 31.4 & \pm 0.4 & 16.9 & \pm 0.03 & 2.5 & \pm 0.01 & 12.3 & \pm 0.05 & 11.8 & \pm 0.01 & & & 43.5 & \pm 0.12 \\
\hline R134a - IX & 31.7 & \pm 0.3 & 19.2 & \pm 0.03 & 2.3 & \pm 0.01 & 12.7 & \pm 0.04 & 11.8 & \pm 0.01 & 0.2 & \pm 0.0 & 46.2 & \pm 0.13 \\
\hline R152a - IX & 31.7 & \pm 0.2 & 18.0 & \pm 0.03 & 2.5 & \pm 0.01 & 12.6 & \pm 0.04 & 11.7 & \pm 0.01 & 0.2 & \pm 0.0 & 45.0 & \pm 0.12 \\
\hline R1234ze(E) - IX & 31.6 & \pm 0.2 & 19.3 & \pm 0.03 & 2.3 & \pm 0.01 & 13.4 & \pm 0.04 & 11.8 & \pm 0.01 & 0.2 & \pm 0.0 & 47.0 & \pm 0.12 \\
\hline R290 - IX & 31.8 & \pm 0.2 & 22.5 & \pm 0.03 & 2.4 & \pm 0.01 & 12.8 & \pm 0.04 & 11.9 & \pm 0.01 & 0.2 & \pm 0.0 & 49.8 & \pm 0.13 \\
\hline R1270 - IX & 31.6 & \pm 0.2 & 23.6 & \pm 0.04 & 2.5 & \pm 0.01 & 11.8 & \pm 0.04 & 11.8 & \pm 0.01 & 0.2 & \pm 0.0 & 49.9 & \pm 0.13 \\
\hline R134a-DX & 42.2 & \pm 0.3 & 20.5 & \pm 0.03 & 2.5 & \pm 0.01 & 12.5 & \pm 0.04 & 11.8 & \pm 0.01 & & & 47.3 & \pm 0.13 \\
\hline R134a - IX & 42.0 & \pm 0.3 & 23.0 & \pm 0.03 & 2.3 & \pm 0.01 & 12.9 & \pm 0.03 & 11.9 & \pm 0.01 & 0.2 & \pm 0.0 & 50.3 & \pm 0.13 \\
\hline R152a - IX & 42.2 & \pm 0.1 & 21.9 & \pm 0.03 & 2.4 & \pm 0.01 & 13.1 & \pm 0.04 & 11.9 & \pm 0.01 & 0.2 & \pm 0.0 & 49.5 & \pm 0.13 \\
\hline R1234ze(E) - IX & 42.3 & \pm 0.1 & 22.5 & \pm 0.03 & 2.5 & \pm 0.01 & 13.8 & \pm 0.04 & 11.9 & \pm 0.01 & 0.2 & \pm 0.0 & 50.9 & \pm 0.14 \\
\hline R290 - IX & 42.2 & \pm 0.2 & 27.8 & \pm 0.04 & 2.3 & \pm 0.01 & 13.0 & \pm 0.04 & 11.9 & \pm 0.01 & 0.2 & \pm 0.0 & 55.2 & \pm 0.15 \\
\hline R1270 - IX & 42.1 & \pm 0.2 & 28.5 & \pm 0.04 & 2.5 & \pm 0.01 & 12.4 & \pm 0.04 & 11.8 & \pm 0.01 & 0.2 & \pm 0.0 & 55.4 & \pm 0.15 \\
\hline
\end{tabular}

Table 6 - Energy consumption for each element during the $24 \mathrm{~h}$-tests

Figure 7 plots in a bar-chart those individual energy consumptions as accumulative to highlight the importance of each one. From this Figure, it is important to remark the small influence of the secondary fluid pump over the total energy consumption. However, it should not be forgotten that the refrigeration plant used in this manuscript corresponds to a small-scale cascade-system so in a real plant this values can vary significantly.

From the experimental results, it can be affirmed that the use of an indirect expansion system always reports an increment of energy consumption due to the presence of a secondary fluid between the refrigeration facility and the cooling service. Using R134a as a refrigerant, the described increment goes from $+3.0 \%$ to $+6.6 \%$ as the heat rejection temperature rises from $18.8^{\circ} \mathrm{C}$ to $42.2 \circ \mathrm{C}$.

Changing the refrigerant of the HT-cycle, the increment of the IX-system energy consumption reaches a minimum with R152a (from $+2.5 \%$ to $+4.4 \%$ ) and a maximum with R1270 (from $+11.4 \%$ to $+17.1 \%)$. The use of R1234ze(E) as a drop-in of R134a entails an increment rated between $+7.5 \%$ and $+8.5 \%$, while the use of R290 as a natural solution increases the energy consumption of the system from $+10.4 \%$ to $+16.5 \%$. In view of these results, it can be concluded that the HFC R152a is the best option in a cascade upgrade from direct to indirect expansion system. 


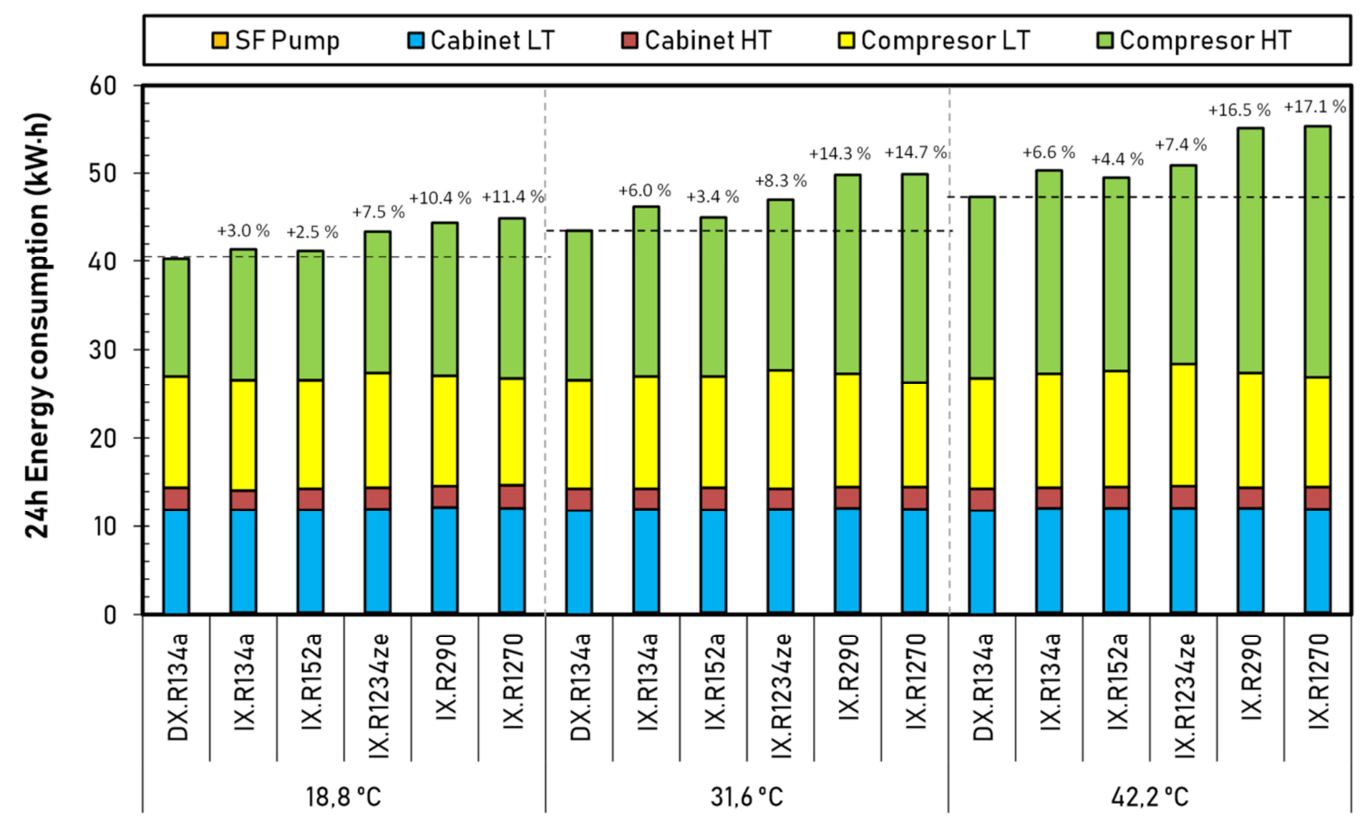

Heat rejection temperature $\left(T_{W, \text { in }}\right)\left({ }^{\circ} \mathrm{C}\right)$

Figure 7. Average energy consumption of the refrigerating plant

Looking at the individual consumptions, no significant differences have been found for cabinets and the secondary fluid pump regardless of the configuration adopted. The average electrical energy consumption registered were $2.4 \pm 0.1 \mathrm{~kW} \cdot \mathrm{h}$ for the MT cabinet, $11.8 \pm 0.1$ $\mathrm{kW} \cdot \mathrm{h}$ for the LT cabinet, and $0.2 \pm 0.0 \mathrm{~kW} \cdot \mathrm{h}$ for the secondary fluid pump.

Concerning the compressors, results from Table 6 evidence that the main cause of the energy differences between configurations are the compressors. In average, the energy consumed by the LT compressor is $12.7 \pm 0.5 \mathrm{~kW} \cdot \mathrm{h}$ whatever the arrangement adopted. However, the averaged electrical energy consumption for the HT compressor is $19.9 \pm 4.3 \mathrm{~kW} \cdot \mathrm{h}$ which evidences the proper selection of the refrigerant and the compressor for the HT-cycle.

In global terms, the $52.6 \%$ of the energy consumed by the experimental cascade is linked to the low-temperature circuit while the $47.4 \%$ is associated with the high-temperature cycle. This means that the relation between the MT and LT cooling capacities are almost 1:1 contrary to the typical relation of 3:1 reported by Sawalha et al. [31] for supermarkets in Northern Europe. The tested relation brings more weight to the LT-cycle which affects the evaporating temperature of the HT-cycle. However, in a typical relation of 3:1 or 4:1, this effect will be weakened by the MT-services.

\section{Environmental analysis}

\subsection{Mass charge reduction}

An important advantage of using indirect expansion system is the reduction of the refrigerant mass charge [17] [32]. To exploit this benefit, a small liquid receiver was installed in the facility when the IX-system was adopted. The main characteristics of this liquid receiver are summarized in Table 1 . Taking into account this particular modification and the use of a 
brazed-plate heat exchanger instead of a finned-tube one (Figures 1 and 2), a significant reduction of refrigerant charge mass was reported according to Table 7.

\begin{tabular}{c|cc|c}
\hline \multicolumn{4}{c}{ REFRIGERANT MASS CHARGE } \\
\hline Configuration & \multicolumn{2}{|c|}{$\mathbf{m}_{\text {Total }}(\mathbf{k g})$} & $\Delta \mathbf{m}_{\text {Total }}(\%)$ \\
\hline R134a - DX & 10.50 & \pm 0.02 & - \\
R134a - IX & 6.02 & \pm 0.02 & $-42.7 \%$ \\
R152a - IX & 3.98 & \pm 0.02 & $-62.1 \%$ \\
R1234ze(E) - IX & 5.00 & \pm 0.02 & $-52.4 \%$ \\
R290 - IX & 3.30 & \pm 0.02 & $-68.6 \%$ \\
R1270 - IX & 3.50 & \pm 0.02 & $-66.7 \%$ \\
\hline
\end{tabular}

\subsection{Total Equivalent Warming Impact (TEWI)}

The parameter of TEWI is devoted to determining the environmental impact of a refrigeration facility in terms of $\mathrm{CO}_{2}$ equivalent emissions (eq. $\mathrm{kg} \mathrm{CO}_{2}$ ). This parameter not only considers the environmental impact due to the refrigerant mass charge (direct effect), but also the electrical energy consumption of the refrigerating plant in a specific period of time (indirect effect). Expression 3 determines the value of TEWI where the direct effect is divided into two terms, the corresponding with the HT-cycle and the associated with the LT-cycle.

$$
\begin{gathered}
\text { TEWI }=\left(\mathrm{GWP}_{\mathrm{RefHT}} \cdot \mathrm{L}_{\mathrm{RefHT}} \cdot \mathrm{n}\right)+\left[\mathrm{GWP} \cdot \mathrm{m}_{\mathrm{RefHT}} \cdot\left(1-\alpha_{\mathrm{RefHT}}\right)\right]+\left(\mathrm{GWP}_{\mathrm{CO} 2} \cdot \mathrm{L}_{\mathrm{CO} 2} \cdot \mathrm{n}\right) \\
+\left[\mathrm{GWP} \cdot \mathrm{m}_{\mathrm{CO} 2} \cdot\left(1-\alpha_{\mathrm{CO} 2}\right)\right]+\left(\mathrm{E}_{\mathrm{year}} \cdot \beta \cdot \mathrm{n}\right)
\end{gathered}
$$

From Expression 3 the following assumptions have been adopted:

a) $G W P_{100}$ represents the global warming potential of the corresponding refrigerant with a time horizon of 100 years. The suffix "RefHT" indicates the refrigerant of the HT-cycle while "CO2" is referred to the LT-cycle. Values for this term are obtained from the IPCC's $5^{\text {th }}$ Assesment Report [33].

b) $L$ is the annual leakage rate that basically depends on the configuration of the refrigerating plant and its age. From literature, a common value of $15 \%$ has been used for DX-systems [34] while for IX-systems a lower value of $5 \%$ has been assumed.

c) $n$ is the operating time-horizon for the refrigerating plant. A typical value of 15 years has been assumed.

d) $m$ is the charge mass of refrigerant according to Table 7. The mass charge of $\mathrm{CO}_{2}$ was $10 \mathrm{~kg}$ in all cases.

e) $\alpha$ is the refrigerant recycling factor when the facility is repaired or modified. From experimental tests, we have calculated this value with the portion of refrigerant not recovered. In average, this factor has a value of $89 \%$ for the HT-cycle, while for the LT-cycle a recycling factor equal to $0 \%$ has been considered since $\mathrm{CO}_{2}$ was not recovered.

f) $B$ is the indirect emission factor due to the electricity generation and depends on the country. For the TEWI evaluation, we have considered the conversion factor of Spain according to the technical data published by IDAE in 2016 [35]: 0.357 eq. $\mathrm{kg} \mathrm{CO} / \mathrm{kW} \cdot \mathrm{h}$.

g) $E_{\text {year }}$ is the yearly energy consumption of the refrigerating plant assuming a working period of 24 hours a day all year round, and specific conditions of heat rejection temperature and cooling demand. In this case, we have assumed the same experimental conditions at the 
cooling demand but different heat rejection temperatures according to the dry-bulb ambient temperatures of the Spanish cities of Almería, Bilbao and Valencia [36]. Taking into account these conditions, the yearly energy consumption of each configuration can be obtained by using the Expression 4 assuming 365 days a year.

$$
E_{\text {year }}=\sum_{i=1}^{365 \text { days }} E_{i}=\sum_{i=1}^{365} \sum_{j=1}^{\text {days }} E_{i j}
$$

The daily energy consumption $E_{i}$ is calculated as a sum of the energy consumption per hour $E_{i j}$ at the corresponding condensing temperature $\left(T_{k, H T}\right)$. This temperature can be determined every hour with the dry-bulb temperature $\left(T_{\text {dry-bulb }}\right)$ assuming a constant temperature difference of $12 \mathrm{~K}$ according to Expression 5 .

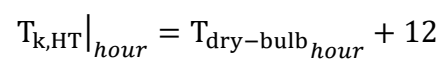

Using the information from the EnergyPlus software, the maximum and the minimum condensing temperature $\left(T_{\mathrm{k}, \mathrm{HT}}\right)$ for each location are Almería: max. $42.8^{\circ} \mathrm{C}$ min. $21^{\circ} \mathrm{C}$; Bilbao: max. $37.5^{\circ} \mathrm{C}$ min. $17.7^{\circ} \mathrm{C}$; Valencia: max. $41.4^{\circ} \mathrm{C}$ min. $18.1^{\circ} \mathrm{C}$. Accordingly, this temperature varies from 18.1 to $42.8^{\circ} \mathrm{C}$ and it fits with the experimental data obtained from tests. Because of this, the energy consumption of the refrigerating plant can be determined from the experimental tests by applying a mathematical interpolation.

To make a more accurate analysis, the following cooling load profile at day has been considered taking into account the operating period presented in references [37, 38]: $100 \%$ of the cooling capacity from $7: 00$ to $22: 00$ and $50 \%$ from $22: 00$ to $7: 00$. This assumption means that the energy consumption decreases by up to $50 \%$ when the supermarket or store is closed.

The results from the environmental analysis are presented in Figure 8 and Table 8 for each indirect cascade configuration at each location analyzed. Below the name of the location, the annual average temperature of the location is also included. 


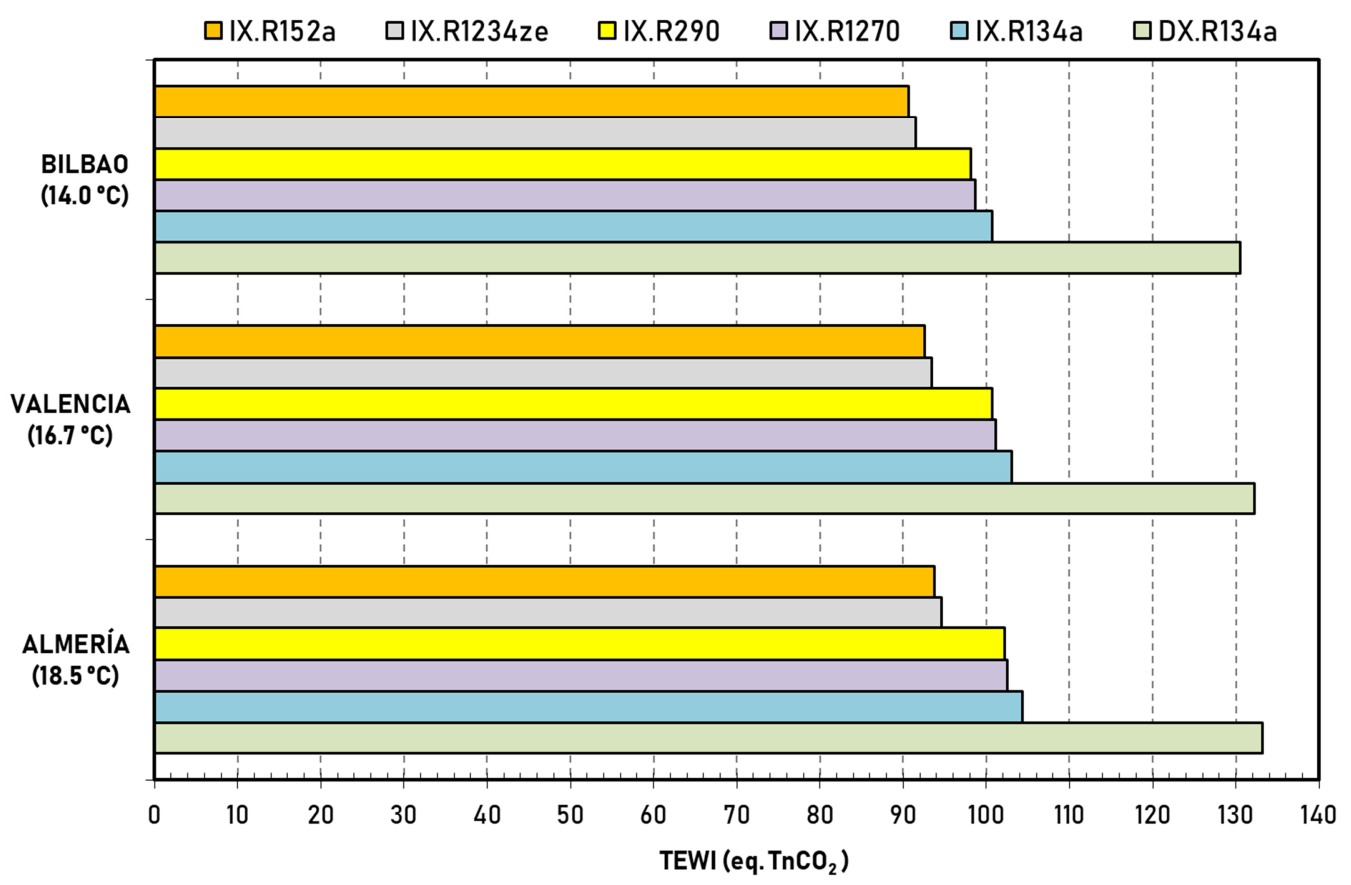

Figure 8. Annual parameter of TEWI for three different Spanish cities

\begin{tabular}{|c|c|c|c|c|c|c|c|c|}
\hline & & & & & & & & \\
\hline & & \multicolumn{7}{|c|}{ TEWI } \\
\hline \multirow[b]{2}{*}{ Location } & \multirow[b]{2}{*}{ Configuration } & \multicolumn{4}{|c|}{ Direct Effect } & \multirow{2}{*}{\multicolumn{2}{|c|}{$\begin{array}{l}\text { Indirect Effect } \\
\text { (eq. Tn } \mathrm{CO}_{2} \text { ) }\end{array}$}} & \multirow[b]{2}{*}{$\begin{array}{c}\text { TOTAL } \\
\text { (eq.Tn } \mathrm{CO}_{2} \text { ) }\end{array}$} \\
\hline & & \multicolumn{2}{|c|}{$\begin{array}{c}\text { Leakages } \\
\left.\text { (eq. } \mathrm{Tn} \mathrm{CO}_{2}\right)\end{array}$} & \multicolumn{2}{|c|}{$\begin{array}{c}\text { Maintenance } \\
\left(\text { eq. Tn } \mathrm{CO}_{2} \text { ) }\right.\end{array}$} & & & \\
\hline \multirow{6}{*}{$\begin{array}{c}\text { Bilbao } \\
\left(\mathrm{T}_{\text {avg year }}: 14.0^{\circ} \mathrm{C}\right)\end{array}$} & R134a-DX & 40.93 & $31.36 \%$ & 1.51 & $1.16 \%$ & 88.06 & $67.48 \%$ & 130.50 \\
\hline & R134a - IX & 7.87 & $7.82 \%$ & 0.87 & $0.87 \%$ & 91.97 & $91.31 \%$ & 100.71 \\
\hline & R152a - IX & 0.58 & $0.64 \%$ & 0.07 & $0.08 \%$ & 90.04 & $99.28 \%$ & 90.69 \\
\hline & R1234ze(E) - IX & 0.04 & $0.04 \%$ & 0.01 & $0.01 \%$ & 91.42 & $99.95 \%$ & 91.46 \\
\hline & R290 - IX & 0.04 & $0.04 \%$ & 0.01 & $0.01 \%$ & 98.13 & $99.95 \%$ & 98.18 \\
\hline & R1270 - IX & 0.04 & $0.04 \%$ & 0.01 & $0.01 \%$ & 98.61 & $99.95 \%$ & 98.66 \\
\hline \multirow{6}{*}{$\begin{array}{c}\text { Valencia } \\
\left(\mathrm{T}_{\text {avg year }}: 16.7^{\circ} \mathrm{C}\right)\end{array}$} & R134a - DX & 40.93 & $30.96 \%$ & 1.51 & $1.14 \%$ & 89.75 & $67.90 \%$ & 132.18 \\
\hline & R134a - IX & 7.87 & $7.64 \%$ & 0.87 & $0.85 \%$ & 94.25 & $91.51 \%$ & 103.00 \\
\hline & R152a - IX & 0.58 & $0.63 \%$ & 0.07 & $0.08 \%$ & 91.97 & $99.30 \%$ & 92.62 \\
\hline & R1234ze(E) - IX & 0.04 & $0.04 \%$ & 0.01 & $0.01 \%$ & 93.42 & $99.95 \%$ & 93.46 \\
\hline & R290 - IX & 0.04 & $0.04 \%$ & 0.01 & $0.01 \%$ & 100.69 & $99.95 \%$ & 100.74 \\
\hline & R1270 - IX & 0.04 & $0.04 \%$ & 0.01 & $0.01 \%$ & 101.07 & $99.95 \%$ & 101.12 \\
\hline \multirow{6}{*}{$\begin{array}{c}\text { Almería } \\
\left(\mathrm{T}_{\text {avg year }}: 18.5^{\circ} \mathrm{C}\right)\end{array}$} & R134a - DX & 40.93 & $30.73 \%$ & 1.51 & $1.13 \%$ & 90.73 & $68.13 \%$ & 133.17 \\
\hline & R134a-IX & 7.87 & $7.54 \%$ & 0.87 & $0.84 \%$ & 95.62 & $91.62 \%$ & 104.37 \\
\hline & R152a-IX & 0.58 & $0.62 \%$ & 0.07 & $0.08 \%$ & 93.08 & $99.31 \%$ & 93.73 \\
\hline & R1234ze(E) - IX & 0.04 & $0.04 \%$ & 0.01 & $0.01 \%$ & 94.60 & $99.95 \%$ & 94.65 \\
\hline & R290 - IX & 0.04 & $0.04 \%$ & 0.01 & $0.01 \%$ & 102.20 & $99.95 \%$ & 102.25 \\
\hline & R1270 - IX & 0.04 & $0.04 \%$ & 0.01 & $0.01 \%$ & 102.51 & $99.95 \%$ & 102.56 \\
\hline
\end{tabular}

Table 8 - Indirect and Direct emission values

Comparing the conversion from direct to indirect expansion, the use of an indirect arrangement allows reducing the TEWI about $22 \%$ on average when R134a is used as a refrigerant. This reduction is higher as lower the annual average temperature is which means that there is an important dependence between TEWI and the environmental temperature (location). Focusing on the direct effect related with annual refrigerant leakages, it represents about $31.0 \%$ of TEWI in the direct expansion arrangement, and an average of $7.7 \%$ when indirect expansion is adopted with R134a. Regarding the direct effect by maintenance operations, it has a marginal influence on TEWI rated between 0.84 to $1.16 \%$. Finally, the impact of the indirect effect on TEWI is higher as higher the heat rejection temperature is. The 
maximum impact on TEWI due to the direct expansion arrangement is $68.13 \%$ while the maximum one for the indirect layout is $91.62 \%$.

Concerning the use of low-GWP refrigerants in the HT-cycle, from Table 8 it can be affirmed that they reduce the total direct effect to almost $0 \%$ (maximum of $0.72 \%$ ). As consequence, the main effect on TEWI is related with the energy power consumption (indirect effect) regardless the refrigerant used. Thus, the use of the R152a allows reducing TEWI up to 30\% on average with respect to the direct expansion arrangement. Similar result is obtained with the HFO R1234ze(E) which reduces TEWI up to $29 \%$ on average when it is used as a direct R134a drop-in. Regarding the hydrocarbons, R290 and R1270 allow shorter the index of TEWI nearly $24 \%$ taking into account that a compressor substitution is mandatory in the refrigerating plant.

According with the results presented above, it worth to remind that these results are obtained with a relation between the MT and LT cooling capacities of almost 1:1 contrary to the typical relation of 3:1 used in supermarkets [31]. Moreover, the refrigerant mass charge is relative small in comparison with a grocery store or a supermarket [32], so it is expected that the values of TEWI presented in Figure 8 as well as its trends, will change in other configurations.

\section{Conclusions}

In this manuscript, a direct expansion R134a/R744 cascade refrigerating plant is experimentally analysed and compared with an indirect arrangement using different low-GWP refrigerants in the high-temperature circuit. The refrigerating facility provides a cooling capacity to a medium temperature cabinet and a horizontal freezer for low temperature, keeping a relation of 1:1 between cooling capacities. The refrigerants used in the HT-cycle corresponds to R134a (A1), R1234ze(E) (A2L), R152a (A2), R290 (A3) and R1270 (A3). For the hydrocarbons propane and propylene, a new compressor was used for security reasons.

From the experimental results is demonstrated that the use of an indirect arrangement always penalizes the energy consumption of the refrigerating plant mainly due to the highest operating time of the HT-cycle compressor. Thus for a heat rejection temperature of $31.6 \mathrm{O} C$, the increment of energy varies from $+14.7 \%$ for R1270 and $+3.4 \%$ for R152a obtaining similar trends with the others temperature levels.

The use of an indirect arrangement allows reducing the refrigerant mass charge on average $58.5 \%$ with a maximum of $68.5 \%$. These values were obtained without optimizing the refrigerating plant, so they can be enhanced by adjusting the capacity of the liquid receiver. The reduction of the mass charge affects the parameter of TEWI which is highly influenced by the energy consumption of the refrigerating facility. The combined effect of both, mass charge and energy consumption provides a TEWI reduction up to $30 \%$ when indirect expansion system is used with R152a.

Taking into account the analysis, it can be affirmed that the HFC- R152a with a GWP 100 of 138 according to the last IPCC's Assessment Report [33], is the best option for an indirect expansion reconversion in the medium temperature level. It allows reducing the mass charge 
of the refrigerant up to $62.1 \%$ with an average energy consumption increment of $+3.4 \%$ and a TEWI reduction of $30 \%$. Moreover, it can be used as a direct drop-in taking into account adequate safety measures according to [10] and [30].

\section{Acknowledgements}

The authors would like to acknowledge the financial support of Jaume I University (projects P11B2015-66 and UJI-B2017-06), the Ministry of Economy and Competitiveness (research project ENE2014-53760-R and grant FPI BES-2015-073612), and finally, the Ministry of Education, Culture and Sports (grant FPU16/00151).

\section{References}

[1] Sharma V., Fricke B., Bansal P., Comparative analysis of various $\mathrm{CO}_{2}$ configurations in supermarket refrigeration systems, International Journal of Refrigeration, 46 (2014) pp. 86-99.

[2] Sanz-Kock C., Llopis R., Sánchez D., Cabello R., Torrella E., Experimental evaluation of a $\mathrm{R} 134 \mathrm{a} / \mathrm{CO}_{2}$ cascade refrigeration plant, Applied Thermal Engineering, 73 (2014) pp. 39-48.

[3] Da Silva A., Bandarra Filho E. P., Antunes A. H. P., Comparison of a R744 cascade refrigeration system with R404A and R22 conventional systems for supermarkets, Applied Thermal Engineering, 41 (2012) pp. 30-35.

[4] Queiroz M. V. A., Panato V. H., Antunes A. H. P., Parise J. A. R., Bandarra Filho E. P., Experimental comparison of a cascade refrigeration system operating with R744/R134a and R744/R404A. International Refrigeration and Air Conditioning Conference. Paper 1785 (2016). http://docs.lib.purdue.edu/iracc/1785

[5] European Commission Regulation (EU) No 517/2014 of the European Parliament and of the Council of 16 April 2014 on Fluorinated Greenhouse Gases and Repealing Regulation (EC) No 842/2006(2014). https://eur-lex.europa.eu/legal-content/EN/TXT/?uri=celex\%3A32014R0517

[6] McLinden M. O., Kazakov A. F., Brown J. S., Domanski P. A., A thermodynamic analysis of refrigerants: Possibilities and tradeoffs for Low-GWP refrigerants, International Journal of Refrigeration, 38 (2014) pp. 80-92.

[7] Domanski P. A., Brignoli R., Brown J. S. , Kazakov A. F., McLinden M. O., Low-GWP refrigerants for medium and high-pressure applications, International Journal of Refrigeration, 84 (2017) pp. 198-209.

[8] Bingming W., Huagen W., Jianfeng L., Ziwen X., Experimental investigation on the performance of $\mathrm{NH}_{3} / \mathrm{CO}_{2}$ cascade refrigeration system with twin-screw compressor, International Journal of Refrigeration, 32 (6) (2009) pp. 1358-1365.

[9] Dopazo J. A., Fernández-Seara J., Experimental evaluation of a cascade refrigeration system prototype with $\mathrm{CO}_{2}$ and $\mathrm{NH}_{3}$ for freezing process applications, International Journal of Refrigeration, 34 (1) (2011) pp. 257-267.

[10] Cabello R., Sánchez D., Llopis R., Catalán J., Nebot-Andrés L., Torrella E., Energy evaluation of $R 152 a$ as drop in replacement for R134a in cascade refrigeration plants, Applied Thermal Engineering, 110 (2017) pp. 972-984. 
[11] Bhattacharyya S., Mukhopadhyay S., Kumar A., Khurana R. K., Sarkar J. , Optimization of a $\mathrm{CO}_{2}-\mathrm{C}_{3} \mathrm{H}_{8}$ cascade system for refrigeration and heating. International Journal of Refrigeration, 28 (8) (2005), pp. 1284-1292.

[12] Dubey A. M., Kumar S., Agrawal G. D., Thermodynamic analysis of a transcritical $\mathrm{CO}_{2}$ /propylene (R744-R1270) cascade system for cooling and heating applications, Energy Conversion and Management, 86 (2014), pp. 774-783.

[13] Xiao J., Liu Y. F., Thermodynamic analysis of a $R 32 / \mathrm{CO}_{2}$ cascade refrigeration cycle. Advanced Materials Research, 732-733 (2013), pp. 527-530.

[14] Bellos E., Tzivanidis C., A theoretical comparative study of $\mathrm{CO}_{2}$ cascade refrigeration system. Applied Sciences, 9 (4), 790 (2019). https://doi.org/10.3390/app9040790

[15] Kazachki G. S., Secondary coolant systems for supermarkets. ASHRAE Journal September 2006 (2006) pp. $34-46$.

[16] Melinder $\AA$., Handbook on indirect refrigeration and heat pump systems. IIF-IIR ISBN: 9782362150104 (2015)

[17] Minea V., Low charge and low emission supermarket refrigeration systems. 8th IIR Gustav Lorentzen Conference on Natural Working Fluids, Copenhagen (Denmark) (2008).

[18] Sharma V., Fricke B., Bansal P., Supermarket refrigeration system charge reduction using cascade systems, 11th IIR Gustav Lorentzen Conference on Natural Working Fluids, China (2014).

[19] Kazachki G. S., Secondary coolant systems for supermarkets. ASHRAE Journal September 2006 (2006) pp. $34-46$.

[20] Llopis R., Sánchez D., Cabello R., Catalán-Gil J., Nebot-Andrés L., Conversion of a direct to an indirect refrigeration system at medium temperature using R-134a and R-507A: An energy impact analysis. Applied Sciences, 8(2), 247 (2018). https://doi.org/10.3390/app8020247

[21] Sánchez D., Cabello R., Llopis R., Catalán-Gil J., Nebot-Andrés L., Energy assessment of an $R 134 a$ refrigeration plant upgraded to an indirect system using $R 152 a$ and $R 1234 z e(E)$ as refrigerants. Applied Thermal Engineering, 139 (2018) pp. 121-134.

[22] Zhang M., Energy analysis of various supermarket refrigeration systems. International Refrigeration and Air Conditioning Conference. Paper 856 (2006). http://docs.lib.purdue.edu/iracc/856

[23] Beshr M., Aute V., Sharma V., Abdelaziz O., Fricke B., Radermacher R., A comparative study on the environmental impact of supermarket refrigeration systems using low GWP refrigerants, International Journal of Refrigeration, 56 (2015) pp. 154-164.

[24] Sawalha S., Perales Cabrejas C., Likitthammanit M., Rogstam J., Nilsson P. O., Experimental investigation of $\mathrm{NH}_{3} / \mathrm{CO}_{2}$ cascade system and comparison with $\mathrm{R}-404 \mathrm{~A}$ system for supermarket refrigeration, $22^{\text {nd }}$ International Congress of Refrigeration, Beijing (China) (2007). 
[25] Sánchez D., Llopis R., Cabello R., Catalán-Gil J., Nebot-Andrés L., Conversion of a direct to

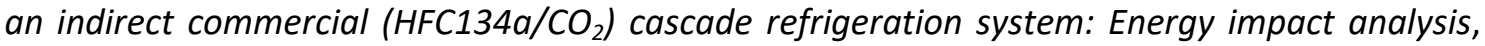
International Journal of Refrigeration, 73 (2017) pp. 183-199.

[26] Llopis R., Sanz-Kock C., Cabello R., Sánchez D., Torrella E., Experimental evaluation of an internal heat exchanger in a $\mathrm{CO}_{2}$ subcritical refrigeration cycle with gas-cooler. Applied Thermal Engineering, 80 (5) (2015) pp. 31-41.

[27] ISO 23953-2:2015. Refrigerated display cabinets - Part 2: Classification, requirements and test conditions. International Organization of Standardization (2015)

[28] Lemmon E.W., Huber M.L., McLinden M.O., Reference fluid thermodynamic and transport properties (REFPROP), NIST Standard Reference Database 23, v.9.1. National Institute of Standards 2013, Gaithersburg MD, USA.

[29] IPU - Refrigeration and Energy Engineering, SecCool Properties v.1.33 (2007). Available in: http://www.en.ipu.dk/Indhold/refrigeration-and-energy-technology/seccool.aspx

[30] Sánchez D., Cabello R., Llopis R., Arauzo I., Catalán-Gil J., Torrella E., Energy performance evaluation of R1234yf, R1234ze(E), R600a, R290 and R152a as low-GWP R134a alternatives, International Journal of Refrigeration, 74 (2017) pp. 269-282.

[31] Sawalha S., Piscopiello S., Karampour M., Manickam L., Rogstam J., Field measurements of supermarket refrigeration systems. Part II: Analysis of HFC refrigeration systems and comparison to $\mathrm{CO}_{2}$ trans-critical. Applied Thermal Engineering, 111 (2017) pp. 170-182.

[32] EPA, Revised Draft Analysis of U.S. Commercial Supermarket Refrigeration Systems (2005)

[33] IPCC/TEAP. Special report: Safeguarding the Ozono layer and the Global climate system. Chapter 4 (2015). https://www.ipcc.ch/pdf/special-reports/sroc/sroc full.pdf

[34] EPA, Transitioning to low-GWP alternatives

https://www.epa.gov/sites/production/files/2016-

12 /documents/international transitioning to low-

gwp alternatives in commercial refrigeration.pdf

[35] Ministerio de Industria, Energía y Turismo, Factores de emisión de $\mathrm{CO}_{2}$ y coeficientes de paso a energía primaria de diferentes fuentes de energía final consumidas en el sector de edificios en España. IDAE (2016). http://www.minetad.gob.es/energia/desarrollo/EficienciaEnergetica/RITE/Reconocidos/Recon ocidos/Otros\%20documentos/Factores emision CO2.pdf

[36] EnergyPlus, DOE, BTO, NREL, EnergyPlus, (2016).

[37] Iyer S. R., Sankar M., Ramakrishna P. V., Sarangan V., Vasan A., Sivasubramaniam A., Energy disaggregation analysis of a supermarket chain using a facility-model. Energy and buildings, 97 (2015) pp. 65-76.

[38] Funder-Kristensen T., Larsen L. F. S., Thorsen J. E., Integration of the hidden refrigeration capacity as heat pump in smart energy systems. $12^{\text {th }}$ IEA Heat pump conference, Rotterdam (Nederland) (2017). 